\title{
A STEP AP 203-214-based machinable volume identifier for identifying the finish-cut machinable volumes from rough-machined parts.
}

ARIVAZHAGAN, A., MEHTA, N.K. and JAIN, P.K.

2009

The final authenticated version is available online at: https://doi.org/10.1007/s00170-008-1659-2. This precopyedited version is made available under the Springer terms of reuse for AAMs:

https://www.springer.com/gp/open-access/publication-policies/aam-terms-of-use 


\title{
A STEP AP 203-214-based machinable volume identifier for identifying the finish-cut machinable volumes from rough- machined parts
}

\author{
A. Arivazhagan \& N. K. Mehta \& P. K. Jain
}

\begin{abstract}
A. Arivazhagan ${ }^{1}$, N. K. Mehta ${ }^{1}$, P. K. Jain ${ }^{1 *}$
${ }^{1}$ Department of Mechanical and Industrial Engineering, Indian Institute of Technology Roorkee, Roorkee 247667, India

*Corresponding author: P. K. Jain (e-mail: pjainfme@iitr.ernet.in)
\end{abstract}

\begin{abstract}
This paper presents a STEP AP203-214-based machinable volume identifier (MVI) to identify the finish-cut machinable volume in prismatic parts by deducting the rough-machined part from the final part. The MVI provides an intermediate link between rough and finish machining computer-aided process planning system for automatic generation of process plans while machining prismatic parts. To calculate the machinable volumes of manufacturing features, the MVI utilizes the output of the feature identifier which contains the information about the dimensional details, edge loops, edges, vertices, coordinate points, and location planes of the features. In this research, a total of 234 features have been considered; out of which, 32 are normal and 202 are tapered. To calculate the machinable volumes for these features, generalized methodologies are developed for 17 basic feature types, each having a varying number of specific features. Initially, the pattern strings are generated for the front and back face of the rough-machined feature and final feature. Then, MVI uses the predefined syntactic pattern strings stored in the strings database and checks with the generated strings of the feature to determine the shape of the machinable volume stored in the volumes database. After determining the shape, one relevant methodology or more (for features having combination of more than one taper) are selected from among the 17 "feature type" specific methodologies developed for finish-cut machinable volume identification. In this article, methodology is presented for one basic feature type which covers 14 features and explained through one case study. The final output from this module is stored as a text file with full dimensional details of machinable volumes for later use inside the machining planning module. The proposed MVI can be used in Computer Integrated Manufacturing Industries as an intermediate linker to achieve a robust manufacturing environment.
\end{abstract}

Keywords: Finish machining; Finish-cutmachinable volumes; Syntactic pattern recognition; Edge loops; Deduction of rough-machined part from the final part

\section{Nomenclature}

[1] $\quad \mathrm{VP}_{(i)} \ldots \ldots \mathrm{VP}_{(n)}$ : Vertex Points; where $i=1,2,3, \ldots \ldots . n$

[2] $\mathrm{X}_{(i)}, \mathrm{Y}_{(i)}, \mathrm{Z}_{(i)}: \mathrm{X}, \mathrm{Y}, \mathrm{Z}$ Coordinate points of a $\mathrm{VP}_{(i)}$; where $i=1,2,3, \ldots \ldots . n$

[3] $\mathrm{e}_{(i)}, . . \mathrm{e}_{(n)}$ : Edges of the feature; where $i=1,2,3, \ldots \ldots . . n$

[4] $\quad \mathrm{EL}_{(i)} \ldots . . \mathrm{EL}_{(n)}$ : Edge Loops of the features constituting edges $\mathrm{e}_{(i)} \ldots \mathrm{e}_{(n)}$; where $i=1,2,3, . . n$

[5] $\quad \mathrm{F}_{(i)}, . . \mathrm{F}_{(n)}:$ Faces of the part or feature; where $i=1,2,3, \ldots \ldots . n$

[6] $\mathrm{T}_{(i) \ldots} \mathrm{T}_{(i)}$ : Temporary point where $i=1,2,3, \ldots \ldots . n$

[7] $\mathrm{R}_{(i)}$ : Radius of the feature; where $i=1,2,3, \ldots \ldots . n$

[8] $\quad r$ and $f$ : Subscript to denote the values of rough-machined part and final part

[9] $l, w$, and $h$ : Length, Width and Height of the finish-cut machinable volume

[10] $t$ : Thickness of the finish-cut machinable volume

[11] $\mathrm{OH}$ and IH: Outer and Inner Height of the finish cut machinable volume

[12] OL and IL: Outer and Inner Length of the finish cut machinable volume

[13] OW and IW: Outer and Inner Width of the finish cut machinable volume

[14] SF: Standard Face;

[15] PQ Face or PQF: Perfect Quadrilateral Face;

[16] FSG: Face with Standard Geometrical shape;

[17] CRF: Circular Face;

[18] CP Face or CPF: Complex Polygon Face;

[19] FWC: Face with a Cavity; 


\section{Introduction}

In computer-aided process planning (CAPP), work on feature recognition for prismatic parts has focused mainly on identifying the machinable volume as a whole. Generally, machining a part starts with a rough cut in which the bulk of the material is removed in the form of simple blocks. The remaining finish-cut volume has to be identified separately to complete the machining of the feature. From the machinist point of view, the finish-cut machinable volume forms the crux of the machining as it contains the details of surface finish and tolerance linked with the final dimensions. This finish-cut machinable volume is often complex in shape as it is bounded by the simple shape of the rough cut on one side and the final shape of the feature on the other. The difficulty in identifying this volume is more pronounced when the features of complicated cross sections such as tapering features, interacting features, and features with curved bases and their interactions are present in the part. In order to understand the complexities associated with feature identification and calculation of removable volumes in prismatic parts, a review of previous research works is necessary.

Nagaraj and Gurumoorthy [1] developed an algorithm to extract the rough machinable volumes to be removed from a stock using a B-Rep data of the part. The developed algorithm is capable of identifying the primitive volumes of different shapes such as cuboids, wedges, and collars for both prismatic and cylindrical parts. A volume decomposition approach has been proposed by Alan and Shou [2] for building an interface between a 3D computer-aided design (CAD) model and an automated process planning system. They used the concept of backward filling where various forms of machining volume are filled to find the machining features and the mass-material removal volume. Ranko and Andrew [3] selected bulk machinable volumes for prismatic parts using an object-oriented approach. They developed algorithms using geometric reasoning to select the machinable volumes required to produce the part and implemented their algorithm in an object-oriented environment. The volumes that are selected in their work concentrate on selecting the rough or bulk volume of material.

An approach to construct geometric feature volumes for free-form surfaces is presented by Lim et al. [4]. They developed a four-step L-algorithm that can recognize features and construct rough machinable volumes. In their work, they defined these volumes in two ways, namely (1) prime machinable volume and (2) additive machinable volume applicable to depression and protrusion type of features. Jain et al. [5] developed a knowledge based interactive CAPP system named UOR_PLAN for rotational components. In their work, two phases, namely (1) macro cut planning for roughing and (2) micro cut planning for finishing, are followed to remove the unwanted material. A feature recognition module for the CAPP system named CAPPS_PRINTER is developed by Hebbal and Mehta [6, 7], in which calculation of rough machinable volumes for prismatic parts has been dealt with. They used DXF format and syntactic pattern recognition technique to recognize the following features: (1) primitive features of depression and protrusion type having both planar and inclined surfaces, (2) certain complex features arising from interaction between primitive features, and (3) a wide range of interacting features. Sandiford and Hinduja [8] constructed separate rough machinable volumes called maximal volumes and developed a feature recognition system that can perform the following four functions to recognize the part: feature detection, (2) volume construction, (3) feature verification, and (4) workpiece updating. Yoonhwan and Hiroshi [9] identified the maximal removal volume termed as delta volume or bulk volume, by comparing the final part with the original stock. In this approach, they recognized the feature by constructing the delta volume and decomposing it into large and simple volumes. Little et al. [10, 11] developed a feature finder using a graph-based approach to identify a feature by generating delta volumes (bulk removal volume) for a wide range of machined components. The feature finder is capable of subdividing the bulk volume of material into a smaller number of volumes based on a feature complexity index for recognizing the manufacturing features. A customizable feature recognizer named Custom-Cut has been developed by Daniel and Caroline [12] to identify the bulk machinable volumes that can be removed by using a cutting tool. The feature recognizer uses a set of cutting tool and machine tool descriptions to remove the volume which is obtained as the difference between the stock and the part.

An automated process planning system for boring of turned components with arbitrary internal geometry from a semifinished stock has been proposed by Satish et al. [13]. In their approach, they followed a six-step process planning sequence and generated NC Codes to manufacture the component. Zhu and Menq [14] presented an approach to simplify B-Rep models by suppressing the secondary features fillet or round for identifying the primary features in prismatic parts. They described two algorithms, namely (1) ring type (KR) and (2) disk type chain (KD) algorithms. which were implemented while suppressing the fillets and rounds in prismatic parts. Fu et al. [15] proposed an approach for identifying the manufacturing features from a STEP protocol for prismatic parts. In their work, they have developed a system that can recognize the machining features from IGES, STEP AP214, DXF, and SAT formats. Two approaches, one for identifying the design features and the other for machining features, were developed. They proposed a feature-based taxonomy method to identify the bulk machinable volume.

Qiang and Michael [16] presented an approach for identifying the interacting features using Dempster-Shafer approach. In their work, they developed different classes of features based on geometric and topological relationshipsat different abstraction levels. Then, they applied evidential reasoning to recognize interacting features. An approach combining the graph-based recognition method with hint-based feature recognition method is presented by Gao and Shah [17] for identifying the 
interacting and the isolated features (noninteracting). Initially, the isolated features are identified based on Manufacturing Face Adjacency Graph. Then, the interacting features are recognized by using a hint of minimal conditional subgraph defined using extended attributed adjacency graph. Godfrey [18] presented an approach on back propagation neural network to recognize the manufacturing features from B- Rep solid model. An approach known as viewer-centered geometric feature recognition is adopted by Sommervillie et al. [19]. They identified the protrusion and depression features by developing a fivestep algorithm based on tomographic methodology.

Shu [20] used 3D CAD data in developing a feature extraction methodology by classifying the rotational parts using a volume decomposition technique. The types of features considered include symmetric, nonsymmetric, concave, convex, and complex features. Featuresapplicable for machining in turning centers are identified from DXF format by Ersan et al. [21]. They developed feature and machining parameters array and tested it in their expert system named "ASALUS" designed for rotational parts. Young et al. [22] presented an approach for automated part recognition using time series analysis and neural networks. They developed signatures and autocorrelation functions which are the invariant to the transformation such as scaling, translation, and rotation. Then, they recognized the features by inputting these details to the neural network developed for the purpose. Projective feature recognition approach has been used by Hyun Chan Lee et al. [23] to recognize nine simple features and their interactions. The nine simple features considered in their work are step, blind step, slot, blind slot, pocket, hole, wedge, fillet, and sector. An approach on machining feature recognition for generating tool paths in three-axis CNC milling machine is presented by Bor-Tyung Sheen and Chun-Fong You [24]. They handled the problem of feature recognition in two view points and developed an algorithm for determining the geometric information of manufacturing features. The two view points are (1) feature interpretation changes with setup direction and (2) acquiring geometric information of manufacturing features including shapes and depths. After this, the tool paths are generated for the three-axis CNC milling.

By analyzing the past research, it is seen that researchers have focused on identifying the features and calculating the machinable volumes for rotational parts $[5,13,20,21]$ using various feature recognition techniques [25] such as pattern recognition [6,7], volumetric decomposition [8,20], attributed adjacency graph [17, 26], syntactic time series analysis and neural networks [22] and projective feature recognition [23]. However, only in [5, 13] a distinction between rough and finish cuts has been made while developing the process plans. The reported work on prismatic parts [3-6, 14-18, 27-29] shows that normal features such as slot, step, pocket, and their interactions are identified. Further, the machinable volumes are calculated only for rough cuts in the form of cuboids, collars, wedges, or their combinations [1, 6, 7]. But, the actual shape of the finishcut machinable volume in prismatic parts is bounded by the simple shape of the rough cut on one side and the final shape of the feature on the other.

When machining prismatic parts with close tolerance and surface-finish requirements, there is a need for more accurate and rigid tooling for the finishing cut as compared to the rough cut. Hence, the distinction between rough and finish cuts is extremely important for selection of machine tool, cutting tool, machining parameters, setup plan, and fixtures. It appears from published literature that this issue has not been addressed in the domain of CAPP for prismatic parts.

Further, it is evident that whenever 3D CAD models are exported in a vendor neutral format between two dissimilar CAD systems or from a CAD system to a feature recognition system, they come into other CAD systems as featureless chunks of geometry entities with less information than that embedded in the original features $[15,29]$. In order to preserve all the information of the original features, it is necessary to "reconstruct" the designed feature information based on geometry and topological entities after they have been translated. To avoid the problems faced in translation, an international standard STEP has been adopted in the present work. STEP CAD formats AP203 and AP214 [30, 31] are different from their predecessors (PDES) and other vendor neutral formats (namely DXF, IGES, Parasolid, etc.) because they support not only 3D product data but also product identification information, assembly structures, configuration-controlled assemblies, and manufacturing features. Hence, it has been decided to develop a machinable volume identifier (MVI) for finish cut based on STEP AP203 and AP214 formats.

While presenting the details of the MVI through this article, the following arrangement is followed: Section 2 describes the MVI developed in this research. Section 3 deals with the general methodology applicable to feature recognition and finish-cut machinable volume calculation. In section 4, a "feature type" specific methodology is presented for "through slot with blending edge." In Section 5, a case study is presented to validate the "feature type." Finally, conclusions are presented in Section 6.

\section{Overview of machinable volume identifier for finish cut}

The schematic representation shown in Fig. 1 represents the feature recognition module with the three submodules, namely (1) Interfacer for STEP AP 203-214 (IFST) (2) Feature Identifier (FI), and (3) machinable volume identifier (MVI). As shown in Fig. 1 , the output data of the feature recognizer in terms of edge loop data, edge and vertex data, coordinate points, and plane information serves as the input for the MVI. The MVI consists of nine submodules to calculate the machinable volume. The following three submodules constitute the primary part in the MVI and are directly connected with the output module of the feature 
recognizer:

1. Edge loop extractor (ELE): The ELE module extracts the information of features regarding the edge loops, dimensions, location planes, and their interactions.

2. Edge and vertex extractor (EVE): The EVE module extracts the details of the edges and vertices along with the coordinate points of the features.

3. Deductor for rough and final part (DRF): The DRF module separates the information of rough and final part, which is required for generating strings and the finish-cut machinable volume calculation.

These three modules are, in turn, connected with the syntactic pattern recognizer (SPR). The SPR contains a syntactic pattern strings database (SPSD) where a database of strings and the shape of machinable volumes are stored. Input to the SPR is from the DRF module. The SPR is directly connected with the finish-cut volume identifier (FCVI) which, in turn, is connected to a checker subsystem. The checker subsystem contains three modules, namely (1) dimensional checker (DC), (2) coordinate plane checker (CPC), and (3) extra volume checker (EVC). These three modules check the dimensions, plane locations, and interactions before the calculation of finish-cut machinable volume. Finally, the FCVI displays the output of MVI on the graphical user interface.

While calculating machinable volumes, there may be many combinations of features in a prismatic part. All these features will be the interactions of the normal features and tapered features. Hence, during this process, standard dimensional details are used to describe the volume. They are length $(l)$, width $(w)$, height $(h)$, and thickness $(t)$. For example, if the feature is an ordinary through slot, the dimensional details linked with the finish-cut volume are as shown in Fig. 2 . Here, $l$ is mentioned as Outer Length (OL) and Inner Length (IL) to describe the machinable volume's outer and inner length. The OL is obtained from the final part and the IL from the rough-machined part. Likewise, $w$ is mentioned as Outer Width (OW) and Inner Width (IW) and $h$ is mentioned as Inner Height (IH) and Outer Height (OH). $t$ is the value obtained by deduction of the roughmachined part from the final part.

Table 1 shows the 17 basic feature types for which methodologies have been developed to identify the finish-cut volume. The number of features covered under each feature type is shown in parenthesis. These 17 basic feature type methodologies are able to cater to a total of 234 features.

\section{General methodology to identify the features and calculation of finish-cut machinable volume}

In order to find the finish-cut machinable volume, it is first necessary to recognize the features in the prismatic part. Feature recognition has been dealt with in an earlier work of the authors [32], and the procedure is briefly summarized in Steps 1-9 (Section 3.1) below. The steps applicable to the present work are discussed in Section 3.2 and are numbered from 10-14 to maintain the continuity. The reader may go through all the steps (1-14) for better understanding of the present work.

\subsection{Steps to identify features}

Step 1: Input rough-machined part and final part to the feature recognition module.

Step 2: View the part from XY, YZ, and ZY directions and identify the faces parallel to these planes.

Step 3: Identify the type of faces on these planes by adopting the standard pattern strings developed for the purpose. Then, group the faces either as face with edge loops or face without edge loops.

Step 4: Implement the concept of edge loops and identify the manufacturing features.

Step 5: Match the parallel edge loop in the same plane and determine whether the feature is a blind feature, a through feature, or an interacting feature.

Step 6: Classify the features according to their subclass as slot, step, pocket, hole, chamfer, or fillet and calculate the necessary dimensions of the feature and part.

Step 7: Identify whether the feature is normal or tapered.

Step 8: If it is tapered, identify the nature of taper.

Step 9: Finally, calculate the taper angle.

3.2 Steps for calculation finish cut machinable volume

\subsubsection{Steps to identify the shape of the finish cut machinable volumes}

Step 10: Identify the shape of the finish-cut machinable volume by separating the information of rough-machined part and final part. 
Substep 10.1: From the output of the feature recognizer, the ELE and EVE separate the information regarding the edge loops, edges, vertices, planes, and dimensions.

Substep 10.2: The DRF separates the details of the edge loops, vertices, and coordinate points for the rough-machined and final part.

Substep 10.3: The arranged data of rough-machined and final part are passed to the SPR for the generation of strings that are compared with the predefined syntactic pattern strings stored in the SPSD database to identify the shape of the machinable volume. Table 2 presents the strings and their corresponding finish-cut volumes for five sample features. The full database contains similar data for 234 features. This step is elaborated with a suitable example in the next paragraph.

Explanation to Substep 10.3: String generation proceeds in an anticlockwise direction from the top left hand corner using the predefined vectors [33] shown in Fig. 3. The vectors containing the strings from "A-T" are applicable for the features slot, step, rectangular pocket, whereas, string " $\mathrm{C}$ " is generated only for single cylindrical feature (i.e., through or blind hole). For generating the strings, the vertex points of front face edges of the rough-machined feature and the final feature are trans- posed and connected to form a closed figure, as shown in Fig. 4. Similarly, the string is generated for the back face of the feature. For the example part of Fig. 4, the string of the finish-cut machinable volume is read as "BADCBCDC." Now, to determine the shape of the machinable volume, the strings of the front and back faces are compared with the predefined strings stored in the strings database.

\subsubsection{Steps to check whether the features are interacting or noninteracting}

Step 11: Identify whether the features are interacting or noninteracting

Using the information extracted from the ELE, the FCVI check whether the features are interacting. For this, the procedure adopted by Hebbal and Mehta [6, 7] (given below) is used. The general steps for feature interaction are as follows:

Substep 11.1: Initially, identify the feature as "through" or "blind" by applying the concept of edge loops.

Substep 11.2: Check whether the face belongs to Perfect Quadrilateral (PQ) category by identifying the connecting face of the feature between the parallel edge loop or parallel face.

Substep 11.3: If all the faces are of PQ category, then assign the feature as "feature with no interaction."

Substep 11.4: If the type of face belongs to Complex Polygonal (CP) Face or Face With a Cavity (FWC), then assign the feature as interacting feature.

Substep 11.5: Now, for the detected face of CP or FWC category, with the help of edge loops, check whether it is "through" or "blind."

Substep 11.6: Perform the same check for other connecting faces.

Substep 11.7: Finally, by analyzing the face contained in the main feature, confirm the features that are interacting with it.

The general steps given above for feature interaction are explained through the example given in Fig 5a-e. In this process, one feature is designated as "initial feature" and then the feature interacting with it is identified and appropriately named.

Explanation to Substep 11.1: Recognize the edge loop $\left(\mathrm{e}_{1}, \mathrm{e}_{2}\right)$ on $\mathrm{CP}$ face $\mathrm{F}_{1}$, (in Fig. 5a- c) which indicates the presence of a feature "step."

Explanation to Substep 11.2: Find identical edge loop $\left(\mathrm{e}_{3}, \mathrm{e}_{4}\right.$; in Fig. $\left.5 \mathrm{a}-\mathrm{c}\right)$ on a parallel $\mathrm{CP}$ face $\mathrm{F}_{2}$ to confirm that the feature identified is a "through step."

Explanation to Substep 11.3: Check whether the two edges $\left(\mathrm{e}_{1}\right.$ and $\left.\mathrm{e}_{2}\right)$ share a PQ type common face with the parallel edge loop $\left(\mathrm{e}_{3}, \mathrm{e}_{4}\right)$. The absence of PQ face in Fig. 5a-c may be due to one of the following three reasons:

Reason (a): The common face $\mathrm{F}_{4}$, instead of being a PQ face, may be a CP face or a face of FWC category with an edge loop, indicating the presence of an interacting feature (Fig. 5a).

Reason (b): The common face has a discontinuity, and there are two coplanar PQ faces between the corresponding edges (Fig. 5b).

Reason (c): The common face $\mathrm{F}_{4}$ has reduced length and, thereby, does not join the edge loops on the parallel faces. The length is reduced due to the presence of an interacting feature (Fig. 5c). 
Explanation to Substep 11.4: A check for the absence of common faces between the corresponding edges of both edge loops under consideration permits us to conclude that the feature is a complex interacting feature having more than one interaction. An additional substep is now required to complete the recognition process of the initial feature and also to identify the interacting feature. The steps for the additional substeps 11.5 to 11.7 are explained only for the "reason (a)" (Fig. 5a), and the others follow the same procedure.

Explanation to Substep 11.5: In Fig. 5d, the common face $\mathrm{F}_{4}$ of $\mathrm{CP}$ type contains the edge loop $\left(\mathrm{e}_{5}, \mathrm{e}_{6}\right.$, and $\left.\mathrm{e}_{7}\right)$. This is considered as the initial loop, and the primitive of the feature "bind slot" is obtained on face $\mathrm{F}_{4}$. Similarly on face $\mathrm{F}_{3}$, the edge loop ( $\mathrm{e}_{8}, \mathrm{e}_{9}, \mathrm{e}_{10}$, and $\left.\mathrm{e}_{11}\right)$ can be used as the initial loop to recognize the primitive of the interacting feature "pocket."

Explanation to Substep 11.7: In previous substeps 11.5 and 11.6, the interacting feature is identified as a new primitive on the common faces of the initial feature. Now, in the substep, the recognition process of the initial feature is completed by neglecting the presence of the interacting feature on the common face so that the common faces $F_{3}$ and $F_{4}$ can be converted into PQ faces as shown in Fig. 5e. Having identified $F_{3}$ and $F_{4}$ as common faces in PQ form, the initial feature is identified now as "through step" and the interacting features are identified as "blind slot" and "blind pocket."

\subsubsection{Steps to reconstruct the interacting feature}

Step 12: Reconstruct the interacting feature as a sum of the constituent features.

Basically, an interacting feature is obtained by machining of the constituent features. Therefore, prior to calculation of the finish-cut volume of an interacting feature, it is necessary to reconstruct the interacting feature as a sum representation of the constituent features. This is implemented in the following substeps:

Substep 12.1: From the EVE, collect the details of edges, vertex points, and coordinate points of the interacting feature.

Substep 12.2: Reconstruct the feature by joining the vertex points of parallel edges omitting the presence of the additional feature.

Substep 12.3: Pass the reconstructed feature to FCVI for calculation of machinable volumes.

The above substeps are explained with the help of Fig. $5 \mathrm{~d}$ and e.

Explanation to Substep 12.1: In Fig. 5d, the feature "through step" is interacting with two features. The edges related to it are $\left(\mathrm{e}_{1}, \mathrm{e}_{2}\right)$ and $\left(\mathrm{e}_{3}, \mathrm{e}_{4}\right)$, and the vertex points are $\mathrm{e}_{1}\left(\mathrm{VP}_{1}, \mathrm{VP}_{2}\right), \mathrm{e}_{2}\left(\mathrm{VP}_{2}, \mathrm{VP}_{3}\right), \mathrm{e}_{3}\left(\mathrm{VP}_{4}, \mathrm{VP}_{5}\right)$, and $\mathrm{e}_{4}$ $\left(\mathrm{VP}_{5}, \mathrm{VP}_{6}\right)$. The corresponding coordinate points are: $\mathrm{VP}_{1}\left(\mathrm{X}_{1}, \mathrm{Y}_{1}, \mathrm{Z}_{1}\right), \mathrm{VP}_{2}\left(\mathrm{X}_{2}, \mathrm{Y}_{2}, \mathrm{Z}_{2}\right), \mathrm{VP}_{3}\left(\mathrm{X}_{3}, \mathrm{Y}_{3}, \mathrm{Z}_{3}\right)$, $\mathrm{VP}_{4}\left(\mathrm{X}_{4}, \mathrm{Y}_{4}, \mathrm{Z}_{4}\right), \mathrm{VP}_{5}\left(\mathrm{X}_{5}, \mathrm{Y}_{5}, \mathrm{Z}_{5}\right)$, and $\mathrm{VP}_{6}\left(\mathrm{X}_{6}, \mathrm{Y}_{6}, \mathrm{Z}_{6}\right)$,

Explanation to Substep 12.2: The feature is reconstructed by connecting the parallel edge loops: (1) the vertex points of edge $e_{1}$ are connected with parallel vertex points in edge $e_{3}$. (2) Similarly, the vertex points of edge $e_{2}$ are connected with the parallel vertex points in edge $\mathrm{e}_{4}$.

Explanation to Substep 12.3: After reconstruction, the feature is ready for calculation of machinable volumes. The reconstructed edges are highlighted as dark lines and shown in Fig. 5e.

The next step is to determine the feature type based on the number of edges, faces, fillet radius, etc. and to calculate the finish-cut machinable volumes. The general methodology applicable to this procedure is given in the next section.

\subsubsection{Steps to calculate the finish cut machinable volume}

Step 13: Calculate the finish cut machinable volume by identifying the suitable "feature type" specific methodology based on the number of edges, faces, fillet radius, chamfer radius, etc.

Substep 13.1: For the obtained shape of the finish-cut machinable volume, the EVE provides the number of edges, faces, fillet radius, and chamfer radius associated with the feature.

Substep 13.2: Based on number of edges, faces, fillet radius, and chamfer radius, identify the appropriate "feature type"Table 1).

Substep 13.3: Apply the "feature type"-specific methodologies to calculate the finish-cut machinable volume by deducting the rough-machined part from the final part.

Explanation to Substep 13.1: If the feature is "through slot" and the shape of the identified finish-cut machinable volume 
is as shown in Fig. 2, then the number of edges is six: three from the edge loop $\mathrm{EL}_{1}\left(\mathrm{e}_{1}, \mathrm{e}_{2}, \mathrm{e}_{3}\right)$ and three from the edge loop $\mathrm{EL}_{2}\left(\mathrm{e}_{4}, \mathrm{e}_{5}, \mathrm{e}_{6}\right)$.

Explanation to Substep 13.2: Here, three edges are identified in both the front and back faces. The "feature types" having three edges on front and back faces are "through slot" (S. no. 2), "blind slot" (S. no. 9), and "through slot with curved base" (S. no. 10) in Table 1. As the feature under consideration hasneither a curved base nor a parallel face, it is decided that the given feature matches with the feature type "through slot."

Explanation to Substep 13.3: The calculation of machinable volume by deduction of the rough-machined part from the final part is carried out in the following steps:

1. Identify the $l$ of the machinable volume by deducting the parallel edges of the edge loops representing the feature in rough part and final part. The calculated length from the rough part constitutes the IL and that from the final part constitutes OL.

2. Identify the $h$ of the machinable volume by deducting the vertices of the edges constituting the side faces of the feature in rough part and final part. This value for the rough-machined part represents IH and the final part represents $\mathrm{OH}$ of the machinable volume.

3. Identify the $\mathrm{w}$ of the machinable volume in rough part and final part by deducting the vertices of the edges constituting the base of the feature. This value for the rough-machined part represents IW and the final part represents OW of the machinable volume.

4. Identify the $t$ of the machinable volume by deducting the edges of the rough-machined part from the final part. This value represents the thickness of the machinable volume in relevant plane and direction.

Step 14: Display the final results with the dimensional details of the machinable volumes.

The procedures detailed in Steps 10-14 are summarized in the form of a flow chart as shown in Fig. 6.

\section{Explanation to "feature type" specific methodology}

Methodologies have been developed for all 17 feature types given in Table 1. However, due to paucity of space, only one is presented here.

\subsection{Feature type: through slot with blending edge}

The edge loops, faces, and vertex points for the above feature type are shown in Fig. 7a and b for the rough-machined and final part, respectively. Inside the SPS, the syntactic pattern recognition string is developed as "BFAEDCBGCHDC"(Fig. 7c) by following the predefined vector. Now, by comparing with the strings data base SPSD (Table 2), the shape of the finish-cut machinable volume is identified (S. no. 5 in Table 2) as shown in Fig. 7d. Now, to calculate the finish-cut machinable volume for the features belonging to the given feature type, the number of edges must be equal to 10 (as provided by EVE). Based on these edges, the dimensions of the finish-cut volume for this feature type are calculated as described below. Due to paucity of space, the calculation procedure is presented only for the rough-machined part as the final part follows the same approach.

\subsubsection{Height (h)}

Height (h) is defined as the distance between the base to top point in a feature. While calculating the height of machinable volume, it is necessary to calculate a temporary point parallel to the base of the feature as the features belonging to this "feature type" contain a blending edge. The procedure to calculate the temporary point is as follows:

Calculation of temporary points for the rough-machined part In Fig. 7a, the points are calculated for the blending edges $\mathrm{e}_{2 \mathrm{r}}$ and $e_{4 r}$ located in the front face $F_{1 r}$. For the edge $e_{2 r}$, the following edges in XY plane are considered: (1) $e_{1 r}$ with VP $\left(X_{1 r}\right.$, $\left.\mathrm{Y}_{1 \mathrm{r}}, \mathrm{Z}_{1 \mathrm{r}}\right)$ and (2) $\mathrm{e}_{3 \mathrm{r}} \mathrm{VP}\left(\mathrm{X}_{2 \mathrm{r}}, \mathrm{Y}_{2 \mathrm{r}}, \mathrm{Z}_{2 \mathrm{r}}\right)$. The temporary point is calculated by drawing two perpendicular lines from the VP $\left(\mathrm{X}_{1 \mathrm{r}}, \mathrm{Y}_{1 \mathrm{r},} \mathrm{Z}_{1 \mathrm{r}}\right)$ and $\mathrm{VP}\left(\mathrm{X}_{2 \mathrm{r}}, \mathrm{Y}_{2 \mathrm{r}}, \mathrm{Z}_{2 \mathrm{r}}\right)$. Then, the intersection point of both the lines is taken as the temporary point. The calculated point is $T_{1 r}=\left(X_{1 r}, Y_{2 r}, Z_{2 r}\right)$.

Similarly for other blending edges, the following points are calculated:

For the blending edge $\mathrm{e}_{4 \mathrm{r}}$, the temporary point is $\mathrm{T}_{2 \mathrm{r}}=\left(\mathrm{X}_{4 \mathrm{r}}, \mathrm{Y}_{3 \mathrm{r}}, \mathrm{Z}_{3 \mathrm{r}}\right)$;

For the blending edge $\mathrm{e}_{7 \mathrm{r}}$, the temporary point is $\mathrm{T}_{3 \mathrm{r}}=\left(\mathrm{X}_{7 \mathrm{r}}, \mathrm{Y}_{8 \mathrm{r}}, \mathrm{Z}_{8 \mathrm{r}}\right)$;

For the blending edge $e_{9 r}$, the temporary point $\mathrm{T}_{4 \mathrm{r}}=\left(\mathrm{X}_{10 \mathrm{r}}, \mathrm{Y}_{9 \mathrm{r}}, \mathrm{Z}_{9_{\mathrm{r}}}\right)$; 
The same procedure is followed to calculate the temporary points in the final part (Fig. 7b).

Calculation of height for rough-machined part In any edge ( $\left.\mathrm{e}_{i}\right)$, the starting point is taken as the Highest VP and the end point is taken as the Lowest VP. These two points are schematically represented in Fig. $7 \mathrm{a}$ for the edges $\mathrm{e}_{1 \mathrm{r}}$ and $\mathrm{e}_{1 \mathrm{f} .}$

$$
\begin{aligned}
& \text { Height }(\mathrm{h})=\left[\text { Diff. of } \mathrm{e}_{1 \mathrm{r}}\right]+ {\left[\text { Low. VP of e } \mathrm{e}_{1 \mathrm{r}}-\mathrm{T}_{1 \mathrm{r}}\right]=\left[\left(\mathrm{X}_{0 \mathrm{r}}, \mathrm{Y}_{0 \mathrm{r}}, \mathrm{Z}_{0 \mathrm{r}}\right)-\left(\mathrm{X}_{1 \mathrm{r}}, \mathrm{Y}_{1 \mathrm{r}}, \mathrm{Z}_{1 \mathrm{r}}\right)\right] } \\
&\left.+\left[\mathrm{X}_{1 \mathrm{r}}, \mathrm{Y}_{1 \mathrm{r}}, \mathrm{Z}_{1 \mathrm{r}}\right)-\left(\mathrm{X}_{1 \mathrm{r}}, \mathrm{Y}_{2 \mathrm{r}}, \mathrm{Z}_{2 \mathrm{r}}\right)\right]=\mathrm{IH} \\
&=\left[\text { Diff. of } \mathrm{e}_{5 \mathrm{r}}\right]+ {\left[\text { Low. VP of } \mathrm{e}_{5 \mathrm{r}}-\mathrm{T}_{2 \mathrm{r}}\right]=\left[\left(\mathrm{X}_{5 \mathrm{r}}, \mathrm{Y}_{5 \mathrm{r}}, \mathrm{Z}_{5 \mathrm{r}}\right)-\left(\mathrm{X}_{4 \mathrm{r}}, \mathrm{Y}_{4 \mathrm{r}}, \mathrm{Z}_{4 \mathrm{r}}\right)\right] } \\
&= {\left[\left(\mathrm{X}_{4 \mathrm{r}}, \mathrm{Y}_{4 \mathrm{r}}, \mathrm{Z}_{4 \mathrm{r}}\right)-\left(\mathrm{X}_{4 \mathrm{r}}, \mathrm{Y}_{3 \mathrm{r}}, \mathrm{Z}_{3 \mathrm{r}}\right)\right]=\mathrm{IH} . }
\end{aligned}
$$

The same procedure is followed for the final part (Fig. 7b) to calculate the other values of $\mathrm{OH}$ of the machinable volume.

Length (l) Length can be defined as the distance covered between front and back point in a part.

Calculation of length for rough-machined part To calculate the $l$ of the machinable volume, the following edges in the roughmachined part are considered: (1) $\mathrm{e}_{3 \mathrm{r}}$ and $\mathrm{e}_{8 \mathrm{r}}$. These edges are shown in Fig. 7a.

$$
\text { Length }(1)=e_{3 r}-e_{8 r}=\left[\left(X_{2 r}, Y_{2 r}, Z_{2 r}\right)\left(X_{3 r}, Y_{3 r}, Z_{3 r}\right)-\left(X_{8 f}, Y_{8 f}, Z_{8 f}\right)\left(X_{9 f}, Y_{9 f}, Z_{9 f}\right)\right]=I L
$$

The same procedure is followed for the final part (Fig. 7b) to calculate the values of OL of the machinable volume.

Width (w) Width can be defined as the distance between two parallel points in the feature. As the feature is having a blending edge, the values of width have to be calculated separately for the base and the top. Hence, the values of the width for IW comprise $\mathrm{w}_{1 \mathrm{r}}, \mathrm{w}_{2 \mathrm{r}}$ (for the base) and $\mathrm{w}_{3 \mathrm{r}}, \mathrm{w}_{4 \mathrm{r}}$ (for the top). The values of the width for OW comprise $\mathrm{w}_{1 \mathrm{f}}, \mathrm{w}_{2 \mathrm{f}}$ (for the base) and $\mathrm{W}_{3} \mathrm{f}, \mathrm{W}_{4 \mathrm{f}}$ (for the top). The schematic representation indicating these notations for the finish-cut machinable volume is given in Fig. 7e. In order to calculate the $w$ of the machinable volume the following parallel edges as shown in Fig. $7 \mathrm{a}$ and $\mathrm{b}$ are considered: (1) $\mathrm{e}_{3 \mathrm{r}}, \mathrm{e}_{8 \mathrm{r}}, \mathrm{e}_{1 \mathrm{r}}, \mathrm{e}_{6 \mathrm{r}}, \mathrm{e}_{5 \mathrm{r}}, \mathrm{e}_{10 \mathrm{r}}$ and (2) $\mathrm{e}_{3 \mathrm{f}}, \mathrm{e}_{8 \mathrm{f}}, \mathrm{e}_{1 \mathrm{f}}, \mathrm{e}_{6 \mathrm{f}}, \mathrm{e}_{5 \mathrm{f}}, \mathrm{e}_{10 \mathrm{f}}$.

\section{Calculation of width for rough-machined part}

$$
\begin{aligned}
& \mathrm{W}_{1 \mathrm{r}}=\text { Diff. between VP of } e_{3 \mathrm{r}}=\mathrm{IW}=\left[\left(\mathrm{X}_{2 \mathrm{r}}, \mathrm{Y}_{2 \mathrm{r}}, \mathrm{Z}_{2 \mathrm{r}}\right)-\left(\mathrm{X}_{3 \mathrm{r}}, \mathrm{Y}_{3 \mathrm{rr}}, \mathrm{Z}_{3 \mathrm{r}}\right)\right] \\
& \mathrm{W}_{2 \mathrm{r}}=\text { Diff. between VP of } \mathrm{e}_{8 \mathrm{r}}=\mathrm{IW}=\left[\left(\mathrm{X}_{8 \mathrm{r}}, \mathrm{Y}_{8 \mathrm{r}}, \mathrm{Z}_{8 \mathrm{r}}\right)-\left(\mathrm{X}_{9 \mathrm{r}}, \mathrm{Y}_{9 \mathrm{r}}, \mathrm{Z}_{9 \mathrm{r}}\right)\right] \\
& \mathrm{w}_{3 \mathrm{r}}=\mathrm{VP} \text { of } \mathrm{e}_{1 \mathrm{r}}-\mathrm{VP} \text { of } \mathrm{e}_{5 \mathrm{r}}=\left[\left(\mathrm{X}_{0 \mathrm{r}}, \mathrm{Y}_{0 \mathrm{r}}, \mathrm{Z}_{0 \mathrm{r}}\right)-\left(\mathrm{X}_{5 \mathrm{r}}, \mathrm{Y}_{5 \mathrm{r}}, \mathrm{Z}_{5 \mathrm{r}}\right)\right]=\mathrm{IW} \text { or } \\
& \mathrm{W}_{3 \mathrm{r}}=\mathrm{VP} \text { of } \mathrm{e}_{1 \mathrm{r}}-\mathrm{VP} \text { of } \mathrm{e}_{5 \mathrm{r}}=\left[\left(\mathrm{X}_{1 \mathrm{r}}, \mathrm{Y}_{1 \mathrm{r}}, \mathrm{Z}_{1 \mathrm{r}}\right)-\left(\mathrm{X}_{4 \mathrm{r}}, \mathrm{Y}_{4 \mathrm{r}}, \mathrm{Z}_{4 \mathrm{r}}\right)\right]=\mathrm{IW} \\
& \mathrm{W}_{4 \mathrm{r}}=\mathrm{VP} \text { of } \mathrm{e}_{6 \mathrm{r}}-\mathrm{VP} \text { of } \mathrm{e}_{10 \mathrm{r}}=\left[\left(\mathrm{X}_{6 \mathrm{r}}, \mathrm{Y}_{6 \mathrm{r}}, \mathrm{Z}_{6 \mathrm{r}}\right)-\left(\mathrm{X}_{1 \mathrm{rr}}, \mathrm{Y}_{11 \mathrm{r}}, \mathrm{Z}_{11 \mathrm{r}}\right)\right]=\mathrm{IW} \text { or } \\
& \mathrm{w}_{4 \mathrm{r}}=\mathrm{VP} \text { of } \mathrm{e}_{6 \mathrm{r}}-\mathrm{VP} \text { of } \mathrm{e}_{10 \mathrm{r}}=\left[\left(\mathrm{X}_{7 \mathrm{r}}, \mathrm{Y}_{7 \mathrm{r}}, \mathrm{Z}_{7 \mathrm{r}}\right)-\left(\mathrm{X}_{10 \mathrm{r}}, \mathrm{Y}_{10 \mathrm{r}}, \mathrm{Z}_{10 \mathrm{r}}\right)\right]=\mathrm{IW}
\end{aligned}
$$

The same procedure is followed for the final part (Fig. 7b) to calculate the other values of OW of the machinable volume.

Thickness ( $t$ ) Thickness can be defined as the amount of material obtained when deducting similar edges of rough-machined feature from the final feature. To find $t$, the following edges are considered: (1) $\mathrm{e}_{1 \mathrm{r}}, \mathrm{e}_{2 \mathrm{r}}, \mathrm{e}_{3 \mathrm{r}}, \mathrm{e}_{4 \mathrm{r}}, \mathrm{e}_{5 \mathrm{r}}$ and $\mathrm{e}_{1 \mathrm{f}}, \mathrm{e}_{2 \mathrm{f}}, \mathrm{e}_{3 \mathrm{f}}, \mathrm{e}_{4 \mathrm{f}}, \mathrm{e}_{5 \mathrm{f}}$ and (2) $\mathrm{e}_{6 \mathrm{r}}, \mathrm{e}_{7 \mathrm{r}}, \mathrm{e}_{8 \mathrm{r}}, \mathrm{e}_{9 \mathrm{r}}, \mathrm{e}_{10 \mathrm{r}}$ and $\mathrm{e}_{6 \mathrm{f}}, \mathrm{e}_{7 \mathrm{f}}, \mathrm{e}_{8 \mathrm{f}}, \mathrm{e}_{9 \mathrm{f}}, \mathrm{e}_{10 \mathrm{f}}$. These edges are represented in Fig. $7 \mathrm{a}$ and $\mathrm{b}$.

$$
\left.\left.e_{1 r}-e_{1 f}=\left[\left(X_{0 r}, Y_{0 r}, Z_{0 r}\right)\left(X_{1 r}, Y_{1 r}, Z_{1 r}\right)\right]-\| X_{0 f}, Y_{0 f}, Z_{0 f}\right)\left(X_{1 f}, Y_{1 f}, Z_{1 f}\right)\right]
$$

Similarly, other values are calculated by deducting the edges of the rough-machined part from the final part.

The above-explained methodology is coded in the $\mathrm{C}$ language running in $\mathrm{VC}++$ compiler and is tested with various combinations of "feature type"-specific methodologies. One of the tested parts is presented as a case study in the next section. 


\section{Case study: calculation of machinable volumes for a simple prismatic part with tapered features interacting with each other}

To explain the methodology, the prismatic part given in Fig. 8 is considered. It contains the following two features: (1) "ordinary through slot with blending edge narrowing at the end" (OTSLBENE) and (2) "ordinary through slot with curved base narrowing at the end" (OTSLCBNE). Both the features are interacting with each other. Due to paucity of space, one feature belonging to the above-explained feature type is presented in the next section. The other feature which belongs to the feature type "through slot with curved base" follows a similar procedure for calculation finish-cut machinable volumes. The output details of the finish-cut machinable volume for both the features are presented in Table 3.

\subsection{Identification of machinable volume for the feature- OTSLBENE}

The partial view of the feature OTSLBENE present in the front face $F_{1 r}, F_{1 f}$ and $F_{1 r}, F_{2 f}$ with the details of rough- machined part and the final part identified through feature recognition are shown in the Fig. 9a and b, respectively. The information extracted by the EVE and ELE is as presented in Table 4. Inside the SPS, the syntactic pattern recognition string is developed as "BFAEDCBGCHDC" by following the predefined vector. Based on the above string, the possible shape of the finish-cut machinable volume is identified as shown in Fig. 9c using the Table 2 (S. no. 5). After identification of the machinable volume, it is checked for interaction. As it is an interacting feature, it is reconstructed using the coordinate point details for the feature presented in Table 4. These details are schematically represented in the Fig. 9a and b. Now, to calculate the finish-cut machinable volume, we have to select the relevant methodology from Table 1. For the given feature in the part, the number of edges is equal to 10 as provided by EVE. Hence, by comparing with the list of methodologies in Table 1, it is found that the given feature belongs to the category "through slot with blending edge." Due to paucity of space, the calculation procedure is presented only for the rough-machined part as the final part follows the same approach. The next section provides thevalidation to the developed methodology.

\subsection{Feature name: OTSLBENE}

\subsubsection{Calculations performed to identify the machinable volumes}

Height As explained in Section 4 under "feature type"- specific methodology, initially, temporary points are calculated separately for the rough-machined part and the final part.

Calculation of temporary points for the rough-machined part In Fig. 9a, the points are calculated for the blending edges $\mathrm{e}_{8 \mathrm{r}}$ and $\mathrm{e}_{10 \mathrm{r}}$ located in the front face $\mathrm{F}_{1 \mathrm{r} .}$. For the edge $\mathrm{e}_{8 \mathrm{r}}$, the following edges in XY plane are considered: (1) $\mathrm{e}_{7 \mathrm{r}}$ with VP $(-20.52$, $-22.60,0.0)$ and $(2) \mathrm{e}_{9 \mathrm{r}}$ with VP $(-27.26,-15.01,0.0)$. The point is calculated by drawing two perpendicular lines from the VP $(-20.52,-22.60,0.0)$ and $(-27.26,-15.01,0.0)$. Then the intersection point of both the lines is taken as the temporary point. The calculated point is $\mathrm{T}_{1 \mathrm{r}}=(-20.52,-15.01,0.0)$.

Similarly for other blending edges the following points are calculated:

For the blending edge $\mathrm{e}_{10 \mathrm{r}}$, the temporary point is $\mathrm{T}_{2 \mathrm{r}}=(-52.54,-15.01,0.0)$;

For the blending edge $\mathrm{e}_{13 \mathrm{r}}$ the temporary point is $\mathrm{T}_{3 \mathrm{r}}=(28.31,-21.96,150.0)$;

For the blending edge $\mathrm{e}_{15 \mathrm{r}}$ the temporary point is $\mathrm{T}_{4 \mathrm{r}}=(45.38,-21.96,150.0)$

Calculation of temporary points for the final part The same procedure is followed in the final part (Fig. 9b) also. The temporary points calculated are as follows:

For the blending edge $\mathrm{e}_{8 \mathrm{f}}$, the temporary point is $\mathrm{T}_{1 \mathrm{f}}=(-14.83,-11.43,0.0)$;

For the blending edge $\mathrm{e}_{10 \mathrm{f}}$, the temporary point is $\mathrm{T}_{2 \mathrm{f}}=(-58.23,-11.43,0.0)$;

For the blending edge $\mathrm{e}_{13 \mathrm{f}}$, the temporary point is $\mathrm{T}_{3 \mathrm{f}}=(50.86,-18.17,150.0)$;

For the blending edge $\mathrm{e}_{15 \mathrm{f}}$, the temporary point is $\mathrm{T}_{4 \mathrm{f}}=(21.9,-18.17,150.0)$; 


$$
\begin{gathered}
\text { Height }(\mathrm{h})=\left[\text { Diff. of } \mathrm{e}_{7 \mathrm{r}}\right]+\left[\text { Low. VP of } \mathrm{e}_{7 \mathrm{r}}-\mathrm{T}_{1 \mathrm{r}}\right]=[(-20.52,-45.43,0.0)(-20.52,-22.60,0.0) \\
+[(-20.52,-22.60,0.0)-(-20.52,-15,01,0.0)]=30: 42 \mathrm{~mm}=\mathrm{IH} \\
=\left[\text { Diff. of } \mathrm{e}_{\mathrm{r}}\right]+\left[\text { Low. VP of } \mathrm{e}_{9 \mathrm{r}}-\mathrm{T}_{2 \mathrm{r}}\right]=[(-52.54,-22.60,0.0)(-52.54,-45.43,0.0)] \\
+[(-52.54,-22.60,0.0)-(-52.54,-15.01,0.0)]=30.42 \mathrm{~mm}=\mathrm{IH}
\end{gathered}
$$

Similarly, the values of other combinations are as follows.

$$
\begin{aligned}
& =\left[\text { Diff. of } \mathrm{e}_{12 \mathrm{r}}\right]+\left[\text { Low. VP of } \mathrm{e}_{12 \mathrm{r}}-\mathrm{T}_{3 \mathrm{r}}\right]=23.47 \mathrm{~mm}=\mathrm{IH} \\
& =\left[\text { Diff. of } \mathrm{e}_{15 \mathrm{r}}\right]+\left[\text { Low. VP of } \mathrm{e}_{15 \mathrm{r}}-\mathrm{T}_{4 \mathrm{r}}\right]=23.47 \mathrm{~mm}=\mathrm{IH}
\end{aligned}
$$

Calculation of height for final part For final part, the values of $\mathrm{OH}$ are found to be 34 and $27.26 \mathrm{~mm}$.

Length To calculate the 1 , the following edges are considered. (1) $\mathrm{e}_{7 \mathrm{r}}, \mathrm{e}_{12 \mathrm{r}}$ and (2) $\mathrm{e}_{7 \mathrm{f}}, \mathrm{e}_{12 \mathrm{f}}$. These edges are represented in Fig. $9 \mathrm{a}$ and $\mathrm{b}$.

\section{Calculation of length for rough-machined part}

$$
\begin{gathered}
\text { Length }(1)=\mathrm{e}_{7 \mathrm{r}}-\mathrm{e}_{12 \mathrm{r}}=[(-20.52,-45.43,0.0)(-20.52,-22.60,0.0)]-[(28.31,-45.43,150.0)(28.31,-26.60,150.0)] \\
=48.83 \text { and } 150 \mathrm{~mm} ; 48.83 \text { and } 150 \mathrm{~mm} ;
\end{gathered}
$$

As the feature lies in the ZY plane, the value of $l$ is taken as $150 \mathrm{~mm}$ (in ZY plane) $=\mathrm{IL}$

Calculation of length for final part

$$
\begin{gathered}
\mathrm{e}_{7 \mathrm{f}}-\mathrm{e}_{12 \mathrm{f}}=[(-14.83,-45.43,0.0)(-14.83,-21.33,0.0)-(50.86,-45.43,150.0)(50.86,-25.76,150.0)] \\
=65.69 \mathrm{~mm} \text { and } 150 \mathrm{~mm} ; 65.69 \mathrm{~mm}, 4.42 \mathrm{~mm} \text { and } 150 \mathrm{~mm}
\end{gathered}
$$

As the feature lies in the $\mathrm{ZY}$ plane the value of $l$ is taken as $150 \mathrm{~mm}$ (in $\mathrm{ZY}$ plane) $=\mathrm{OL}$

Width As explained in the previous section, the values of width have to be calculated for the base and the top. Hence, the values of the width for IW are $w_{1 \mathrm{r}}, w_{2 \mathrm{r}}$ (for the base) and $w_{3 \mathrm{r}}, w_{4 \mathrm{r}}$ (for the top). The values of the width for OW are $w_{1 \mathrm{f}}, w_{2 \mathrm{f}}$ (for the base) and $w_{3 \mathrm{f}}, w_{4 \mathrm{f}}$ (for the top). To calculate the $w$ of the machinable volume, the following parallel edges, as shown in Fig. 9a and b, are considered: (1) $\mathrm{e}_{9 \mathrm{r}}, \mathrm{e}_{14 \mathrm{r}}, \mathrm{e}_{7 \mathrm{r}}, \mathrm{e}_{12 \mathrm{r}}, \mathrm{e}_{11 \mathrm{r}}, \mathrm{e}_{15 \mathrm{r}}$ and (2) $\mathrm{e}_{9 \mathrm{f}}, \mathrm{e}_{14 f}, \mathrm{e}_{7 f}, \mathrm{e}_{12 f}, \mathrm{e}_{11 f}, \mathrm{e}_{15 f}$.

\section{Calculation of width for rough-machined part}

$$
\begin{aligned}
& w_{1 r}=\text { Diff. between VP of } e_{9 r}=[(-27.26,-15.01,0.0)-(-46.76,-15.01,0.0)]=\mathbf{1 9 . 5} \mathbf{m m}=I W \\
& w_{2 r}=\text { Diff. between VP of } e_{14 r}=[(31.34,-21.96,150.0)-(-41.59,-21.96,150.0)]=\mathbf{1 0 . 2 5} \mathbf{m m}=I W \\
& w_{3 r}=\text { Low VP of } e_{7 r}-V P \text { of } e_{12 r}=[(-20.52,-22.60,0.0)-(-52.54,22.60,0.0)]=\mathbf{3 2 . 0 2} \mathbf{m m}=I W \\
& w_{4 r}=\text { Low VP of } e_{11 r}-V P \text { of } e_{15 r}=[(28.31,-26.60,150.0)-(45.38,-26.60,150.0)]=\mathbf{1 7 . 0 7} \mathbf{m m}=I W
\end{aligned}
$$

Calculation of width for final part The same procedure is followed for the final part to calculate the other values of OW of the machinable volume. The values of OW are found to be 43.40,28.65, 28.86, 16.86, and $35.8 \mathrm{~mm}$.

Thickness To find $t$, the following edges are considered: (1) $\mathrm{e}_{7 \mathrm{r}}, \mathrm{e}_{8 \mathrm{r}}, \mathrm{e}_{9 \mathrm{r}}, \mathrm{e}_{10 \mathrm{r}}, \mathrm{e}_{11 \mathrm{r}}$ and $\mathrm{e}_{7 \mathrm{f}}, \mathrm{e}_{8 \mathrm{f}}, \mathrm{e}_{9 \mathrm{f}}, \mathrm{e}_{10 \mathrm{f}}, \mathrm{e}_{11 \mathrm{f}}$ and (2) $\mathrm{e}_{12 \mathrm{r}}, \mathrm{e}_{13 \mathrm{r}}$, $\mathrm{e}_{14 \mathrm{r}}, \mathrm{e}_{15 \mathrm{r}}, \mathrm{e}_{16 \mathrm{r}}$ and $\mathrm{e}_{12 \mathrm{f}}, \mathrm{e}_{13 \mathrm{f}}, \mathrm{e}_{14 \mathrm{f}}, \mathrm{e}_{15 \mathrm{f}}, \mathrm{e}_{16 \mathrm{f}}$.

$\mathrm{EL}_{3 \mathrm{r}}$ and $\mathrm{EL}_{4 \mathrm{r}}$ are considered.

$$
\mathrm{e}_{7 \mathrm{r}}-\mathrm{e}_{7 \mathrm{f}}[(-20.52,-45.43,0.0)(-20.52,-22.60,0.0)]-[(-14.83,-45.43,0.0)(-14.83,-21.33,0.0)]=\mathbf{5 . 6 9} \mathbf{m m} \text { in XY plane }
$$

Similarly, other values are calculated by deducting the edges of the rough-machined part from the final part. The values of thickness are found to be $6.32,5.48 \mathrm{~mm}$. The schematic representation indicating these notations for the finish-cut 
machinable volume is given in Fig. 9c.

\section{Conclusions}

The basic initiative behind this approach is to identify the finish-cut machinable volume left after rough cut using STEP AP203 and AP214 formats. From the literature, it is clear that no such work has been reported so far in the domain of CAPP. For this, an MVI for finish cut has been developed to calculate the finish-cut machinable volume. For all the 234 (normal and tapered) features considered in this research, one relevant methodology or more are selected from among the 17 "feature type"-specific methodologies developed for calculation of finish-cut machinable volume. All the steps to calculate the finish-cut machinable volume are developed as modules of MVI using C programming language running in $\mathrm{VC}++$ compiler. The part details of some standard industrial prismatic parts are inputted manually into the MVI and tested for its capability. The MVI took only 3-4 min to calculate the finish-cut machinable volume. By identifying the finish-cut machinable volume, it is possible to produce a prismatic part with the specified tolerance and surface finish mentioned in the design. This finish-cut machinable volume is useful in machining planning module for the selection of suitable machining processes and operations. 


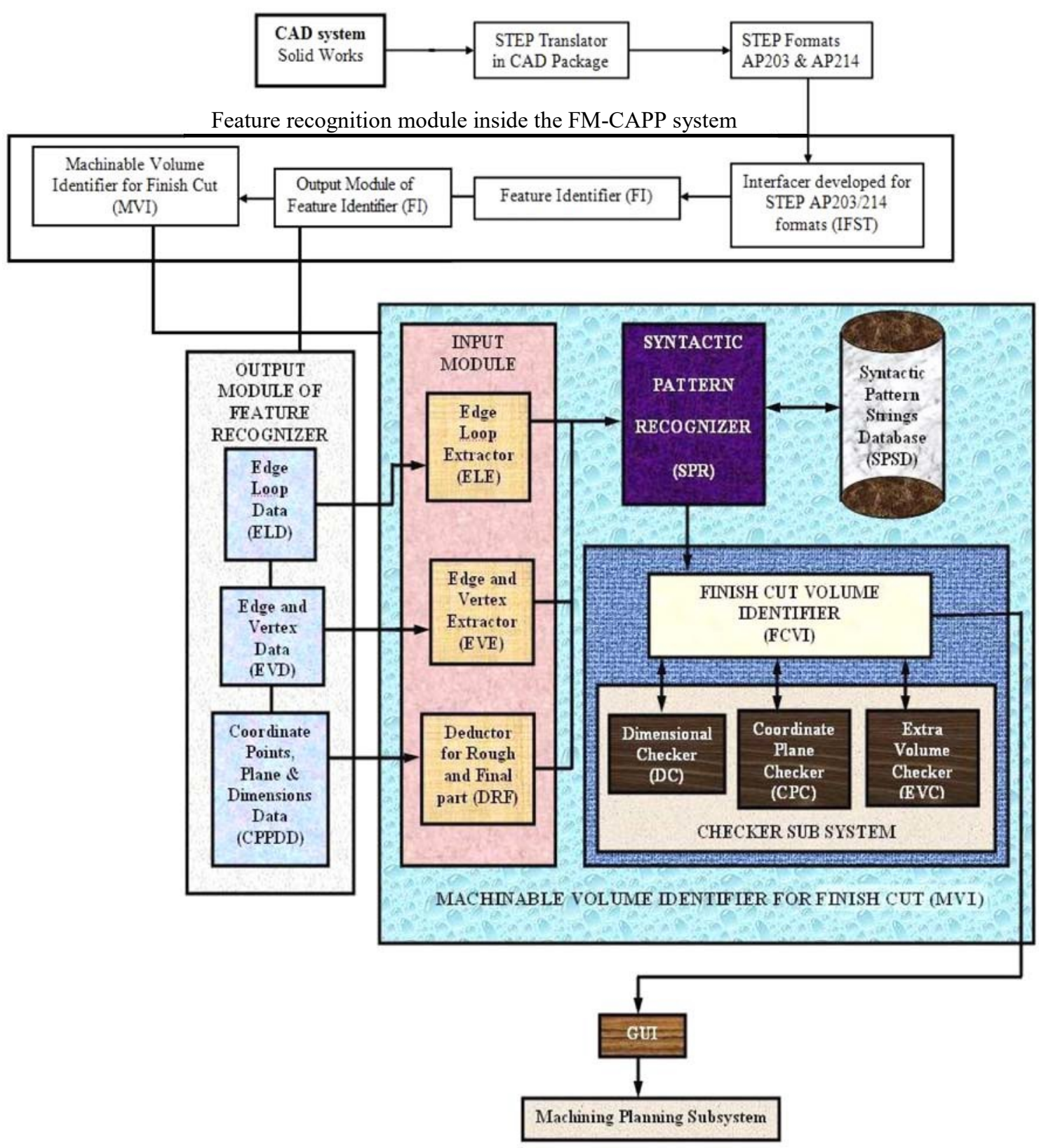

Fig. 1 Block diagram of the feature recognition module in FMCAPP and MVI for finish cut 

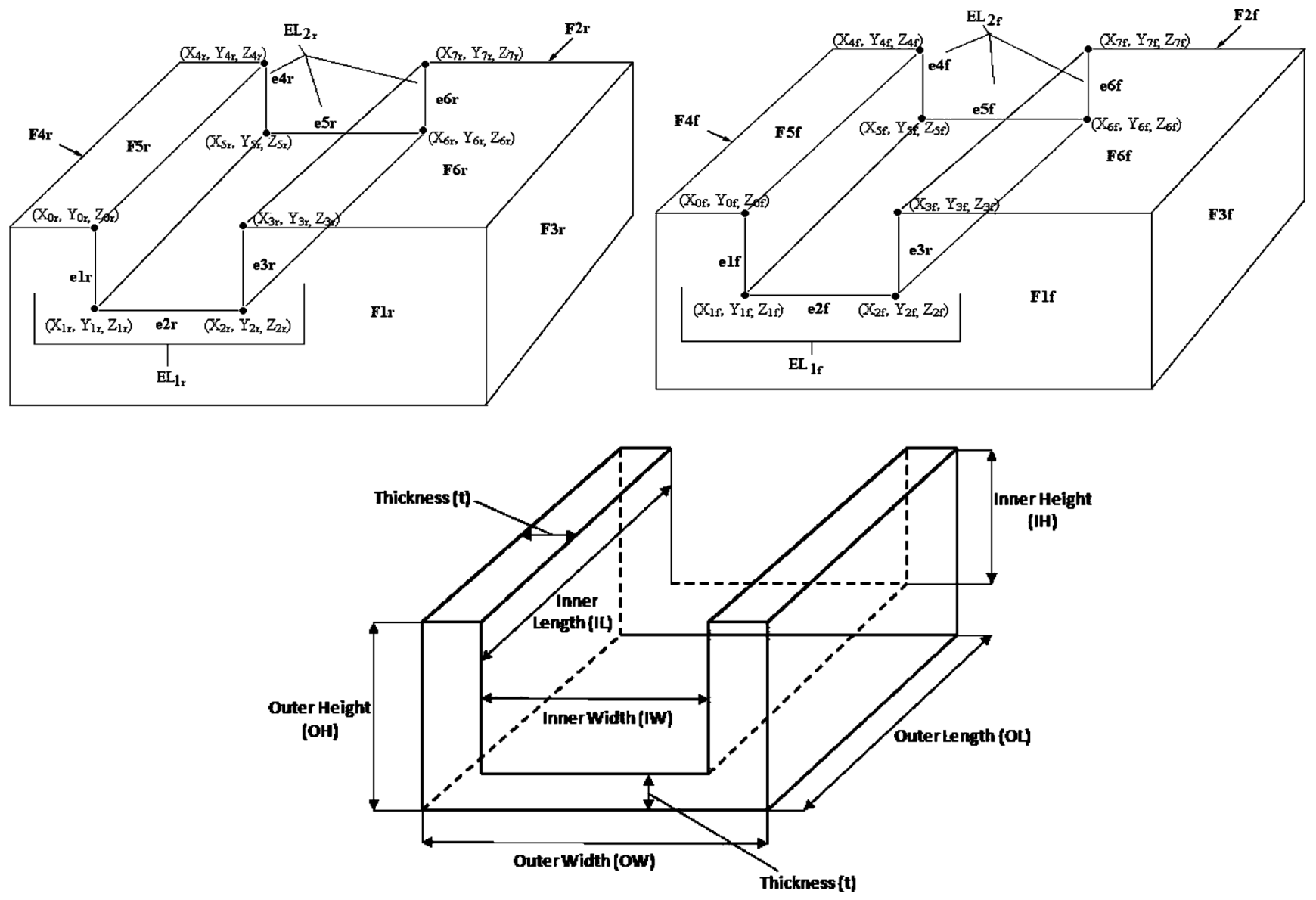

Fig. 2 Machinable volume details for a through slot 
Table 1 Explanation to the 17 feature types

\begin{tabular}{|c|c|c|c|}
\hline S.No & $\begin{array}{l}\text { Name of the 'feature } \\
\text { type' and number of } \\
\text { applicable features }\end{array}$ & $\begin{array}{l}\text { Schematic representation of the 'feature } \\
\text { type' (final feature is given) }\end{array}$ & $\begin{array}{l}\text { Feature description and } \\
\text { its characteristic } \\
\text { parameters (edges, face } \\
\text { etc) }\end{array}$ \\
\hline 1 & $\begin{array}{l}\text { Through step } \\
21\end{array}$ & elf & $\begin{array}{l}\text { This 'feature type' is } \\
\text { used to calculate the } \\
\text { finish cut volume for the } \\
\text { features belonging to the } \\
\text { family 'through step'. } \\
\text { Number of edges: } 4\end{array}$ \\
\hline 2 & $\begin{array}{l}\text { Through slot } \\
21\end{array}$ & & $\begin{array}{l}\text { This 'feature type' is } \\
\text { used to calculate the } \\
\text { finish cut volume for the } \\
\text { features belonging to the } \\
\text { family through slot. } \\
\text { Number of edges: } 6\end{array}$ \\
\hline 3 & $\begin{array}{l}\text { Blind step } \\
21\end{array}$ & & $\begin{array}{l}\text { This 'feature type' is } \\
\text { used to calculate the } \\
\text { finish cut volume for the } \\
\text { features belonging to the } \\
\text { family blind step. } \\
\text { Number of edges: } 3 \\
\text { Number of parallel face } \\
: 1\end{array}$ \\
\hline 4 & $\begin{array}{l}\text { Through Slot with } \\
\text { Filleted corners } \\
6\end{array}$ & & $\begin{array}{l}\text { This 'feature type' is } \\
\text { used to calculate the } \\
\text { finish cut volume for the } \\
\text { features belonging to the } \\
\text { family through slot with } \\
\text { filleted corners. } \\
\text { Number of edges: } 6 \\
\text { Number of Fillet Radius } \\
R: 4\end{array}$ \\
\hline
\end{tabular}




\begin{tabular}{|c|c|c|c|}
\hline S.No & $\begin{array}{l}\text { Name of the 'feature } \\
\text { type' and number of } \\
\text { applicable features }\end{array}$ & $\begin{array}{l}\text { Schematic representation of the 'feature } \\
\text { type' (final feature is given) }\end{array}$ & $\begin{array}{l}\text { Feature description and } \\
\text { its characteristic } \\
\text { parameters (edges, face } \\
\text { etc) }\end{array}$ \\
\hline 5 & $\begin{array}{l}\text { Through Slot with } \\
\text { Blending Edge } \\
14\end{array}$ & FAf & $\begin{array}{l}\text { This 'feature type' is } \\
\text { used to calculate the } \\
\text { finish cut volume for the } \\
\text { features belonging to the } \\
\text { family through slot with } \\
\text { blending edge. } \\
\text { Number of edges: } 10 \\
\text { Temporary Points are } \\
\text { required for identifying } \\
\text { the machinable volumes. }\end{array}$ \\
\hline 6 & $\begin{array}{l}\text { Through V Slot } \\
12\end{array}$ & & $\begin{array}{l}\text { This 'feature type' is } \\
\text { used to calculate the } \\
\text { finish cut volume for the } \\
\text { features belonging to the } \\
\text { family through v slot. } \\
\text { Number of edges: } 4\end{array}$ \\
\hline 7 & $\begin{array}{l}\text { Through Slot with V- } \\
\text { Base } \\
7\end{array}$ & & $\begin{array}{l}\text { This 'feature type' is } \\
\text { used to calculate the } \\
\text { finish cut volume for the } \\
\text { features belonging to the } \\
\text { family through slot with } \\
\text { v base. } \\
\text { Number of edges: } 8\end{array}$ \\
\hline 8 & $\begin{array}{l}\text { Through rectangular } \\
\text { Pocket with Filleted } \\
\text { Corners } \\
2\end{array}$ & & $\begin{array}{l}\text { This 'feature type' is } \\
\text { used to calculate the } \\
\text { finish cut volume for the } \\
\text { features belonging to the } \\
\text { family through } \\
\text { rectangular pocket with } \\
\text { filleted corners. } \\
\text { Number of edges: } 8 \\
\text { Number of Fillet Radius } \\
\text { R: } 8\end{array}$ \\
\hline
\end{tabular}




\begin{tabular}{|c|c|c|c|}
\hline S.No & $\begin{array}{l}\text { Name of the 'feature } \\
\text { type' and number of } \\
\text { applicable features }\end{array}$ & $\begin{array}{l}\text { Schematic representation of the 'feature } \\
\text { type' (final feature is given) }\end{array}$ & $\begin{array}{l}\text { Feature description and } \\
\text { its characteristic } \\
\text { parameters (edges, face } \\
\text { etc) }\end{array}$ \\
\hline 9 & $\begin{array}{l}\text { Blind Slot } \\
21\end{array}$ & F1f & $\begin{array}{l}\text { This 'feature type' is } \\
\text { used to calculate the } \\
\text { finish cut volume for the } \\
\text { features belonging to the } \\
\text { family blind slot. } \\
\text { Number of edges: } 3 \\
\text { Number of parallel face } \\
: 1\end{array}$ \\
\hline 10 & $\begin{array}{l}\text { Through Slot with } \\
\text { curved base } \\
14\end{array}$ & & $\begin{array}{l}\text { This 'feature type' is } \\
\text { used to calculate the } \\
\text { finish cut volume for the } \\
\text { features belonging to the } \\
\text { family through slot with } \\
\text { curved base. } \\
\text { Number of edges: } 6 \\
\text { Number of edges with } \\
\text { curved base : } 2\end{array}$ \\
\hline 11 & $\begin{array}{l}\text { Through step with } \\
\text { Blending Edge } \\
14\end{array}$ & & $\begin{array}{l}\text { This 'feature type' is } \\
\text { used to calculate the } \\
\text { finish cut volume for the } \\
\text { features belonging to the } \\
\text { family through step with } \\
\text { blending edge. } \\
\text { Number of edges: } 6 \\
\text { Temporary Points are } \\
\text { calculated for } \\
\text { identifying the } \\
\text { machinable volumes }\end{array}$ \\
\hline 12 & $\begin{array}{l}\text { T-slot } \\
14\end{array}$ & & $\begin{array}{l}\text { This 'feature type' is } \\
\text { used to calculate the } \\
\text { finish cut volume for the } \\
\text { features belonging to the } \\
\text { family T-slot. } \\
\text { Number of edges: } 14\end{array}$ \\
\hline
\end{tabular}




\begin{tabular}{|c|c|c|c|}
\hline S.No & $\begin{array}{l}\text { Name of the feature } \\
\text { type' and number of } \\
\text { applicable features }\end{array}$ & $\begin{array}{l}\text { Schematic representation of the feature } \\
\text { type' (final feature is given) }\end{array}$ & $\begin{array}{l}\text { Feature description and } \\
\text { its characteristic } \\
\text { parameters (edges, face } \\
\text { etc) }\end{array}$ \\
\hline 13 & $\begin{array}{l}\text { Through Rectangular } \\
\text { hole } \\
12\end{array}$ & & $\begin{array}{l}\text { This feature type is } \\
\text { used to calculate the } \\
\text { finish cut volume for the } \\
\text { features belonging to the } \\
\text { family through } \\
\text { rectangular hole. } \\
\text { Number of edges: } 8\end{array}$ \\
\hline 14 & $\begin{array}{l}\text { Step with Curved } \\
\text { Corner } \\
10\end{array}$ & $\mathrm{~F} 3 \mathrm{f}$ & $\begin{array}{l}\text { This feature type' is } \\
\text { used to calculate the } \\
\text { finish cut volume for the } \\
\text { features belonging to the } \\
\text { family step with curved } \\
\text { corner. } \\
\text { Number of edges: } 6 \\
\text { Number of Curved } \\
\text { Corners: } 2\end{array}$ \\
\hline 15 & $\begin{array}{l}\text { Through step with } \\
\text { filleted corners } \\
6\end{array}$ & $\mathrm{FH}$ & $\begin{array}{l}\text { This feature type is } \\
\text { used to calculate the } \\
\text { finish cut volume for the } \\
\text { features belonging to the } \\
\text { family through step with } \\
\text { filleted corners. } \\
\text { Number of edges: } 6 \\
\text { Number of Fillet Radius } \\
\text { (R) : } 2\end{array}$ \\
\hline 16 & $\begin{array}{l}\text { Chamfer } \\
12\end{array}$ & e10t & $\begin{array}{l}\text { This feature type' is } \\
\text { used to calculate the } \\
\text { finish cut volume for the } \\
\text { features that requires } \\
\text { chamfered edges. } \\
\text { Number of edges: } 6 \\
\text { Number of chamfer edge } \\
\text { details : } 2\end{array}$ \\
\hline 17 & $\begin{array}{l}\text { Through Circular Hole } \\
10\end{array}$ & & $\begin{array}{l}\text { This feature type' is } \\
\text { used to calculate the } \\
\text { finish cut volume for the } \\
\text { features belonging to the } \\
\text { family through circular } \\
\text { hole. } \\
\text { Number of edges with } \\
\text { Radius (R) of the circle : } 2\end{array}$ \\
\hline
\end{tabular}


Table 2 List of features with machinable volumes and strings - normal features

\begin{tabular}{|c|c|c|c|c|}
\hline $\begin{array}{l}\text { S.No } \\
\text { Feature name } \\
\text { and class }\end{array}$ & Feature shape & $\begin{array}{l}\text { Feature } \\
\text { code }\end{array}$ & Finish cut volume & Pattern sting \\
\hline $\begin{array}{l}\text { 1. Ordinary } \\
\text { Through Slot } \\
\text { Slot Class }\end{array}$ & & OTSL & & $\underset{\mathrm{BADCBCDCB}}{\stackrel{\|_{\mathrm{A}}^{\mathrm{D}}}{\stackrel{C}{\longrightarrow}}}$ \\
\hline $\begin{array}{l}\text { 2. Ordinary } \\
\text { Rectangular } \\
\text { Blind Pocket / } \\
\text { Hole } \\
\text { Pocket / Hole } \\
\text { Class }\end{array}$ & & ORBPH & & ABCD \\
\hline $\begin{array}{l}\text { 3. Ordinary } \\
\text { Through } \\
\text { Dovetail Slot } \\
\text { Slot Class }\end{array}$ & & OTBSL & & $\underset{\text { GAHCFCEC }}{{ }^{A}{ }^{{ }^{G}}}$ \\
\hline $\begin{array}{l}\text { 4. Ordinary } \\
\text { Through Slot } \\
\text { with Curved } \\
\text { Base } \\
\text { Slot Class }\end{array}$ & & OTSLCB & & BIDCBJDC \\
\hline $\begin{array}{l}\text { 5. Ordinary } \\
\text { Through Slot } \\
\text { with Blending } \\
\text { Edge } \\
\text { Slot Class }\end{array}$ & & OTSLBE & & BFAEDCBGCHDC \\
\hline
\end{tabular}


Fig. 3 Vectors to generate strings
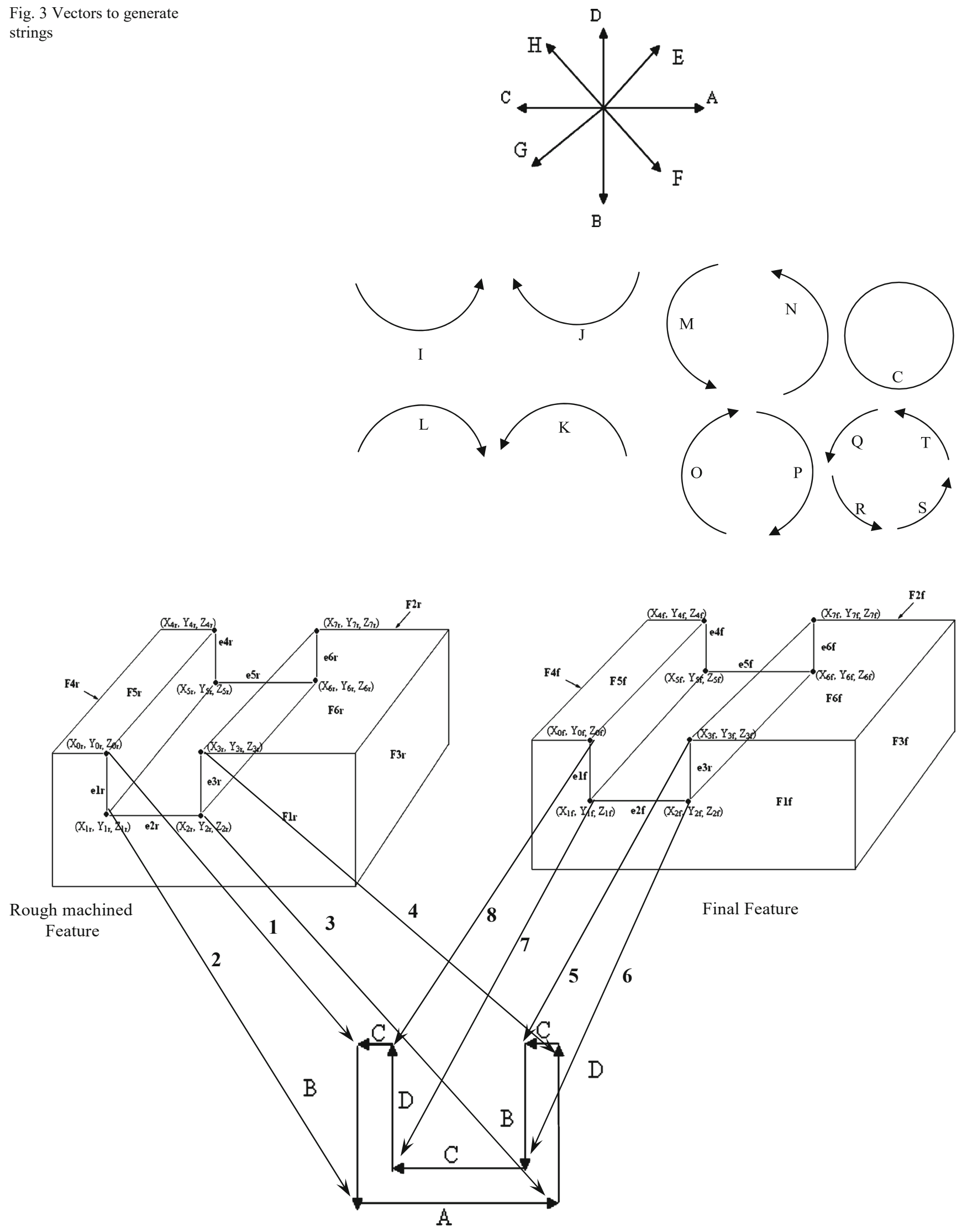

Fig. 4 Generation of strings 


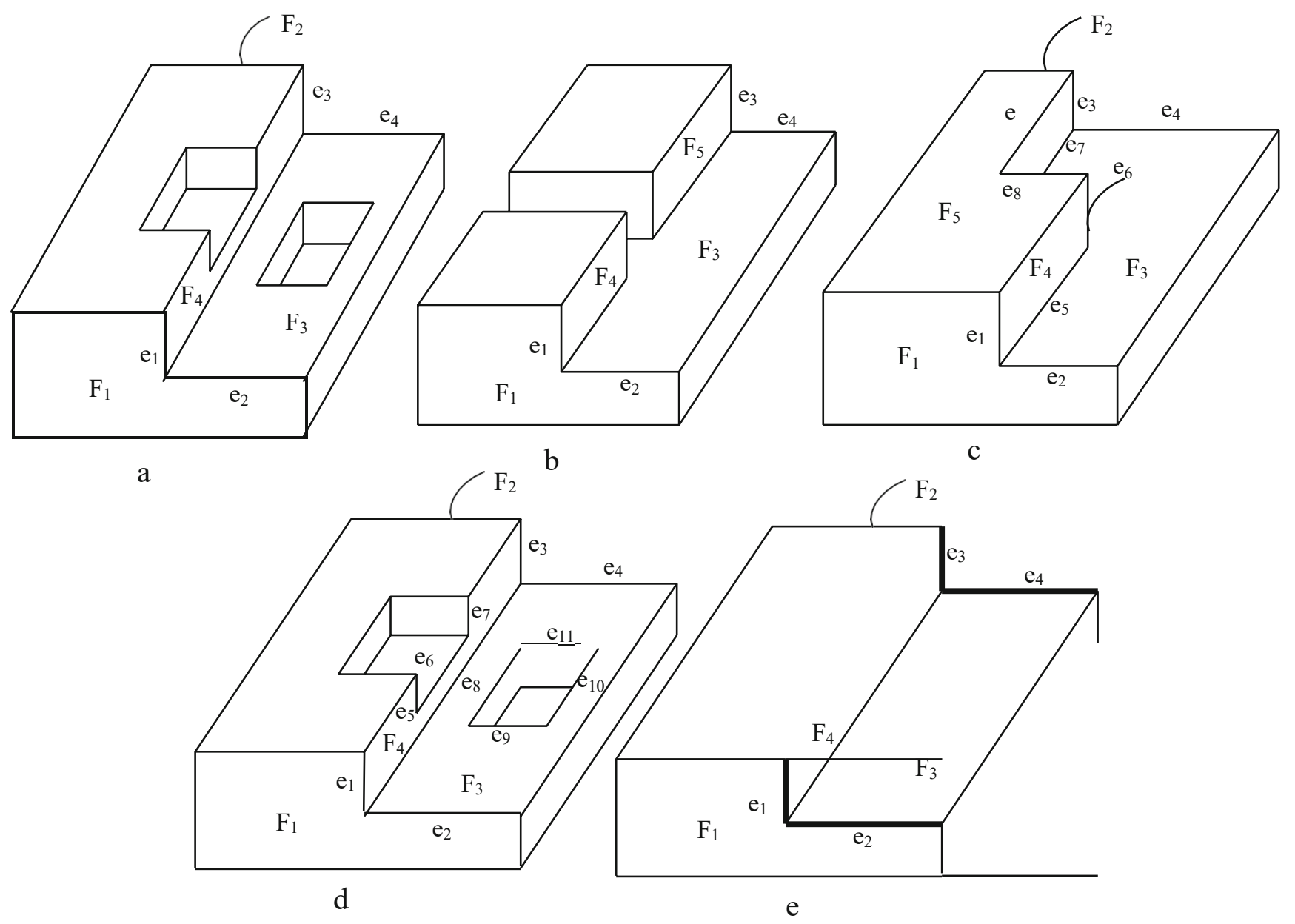

Fig. 5 a, b, c, d, e Example prismatic 
Fig. 6 Flow chart for machinable volume calculation

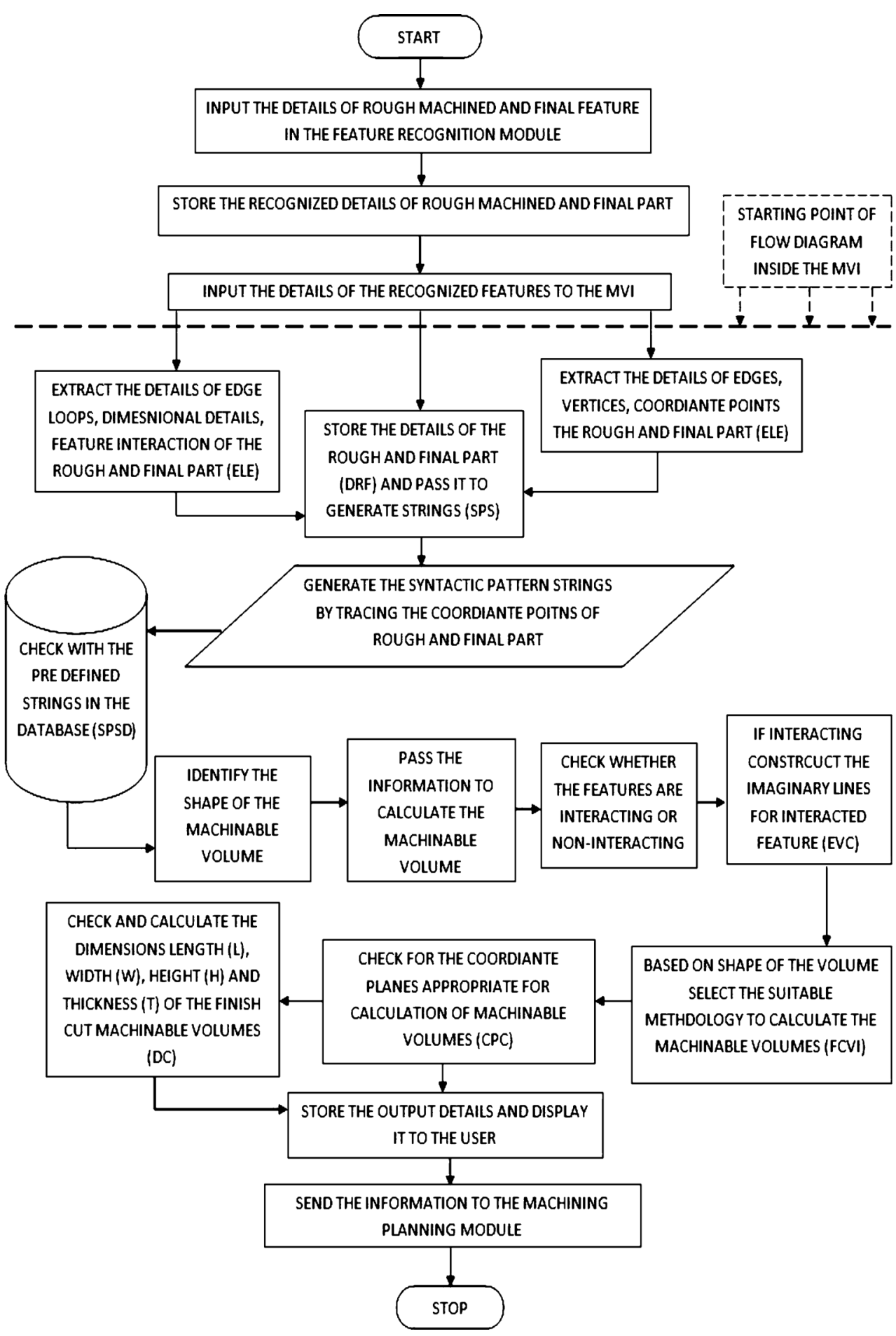




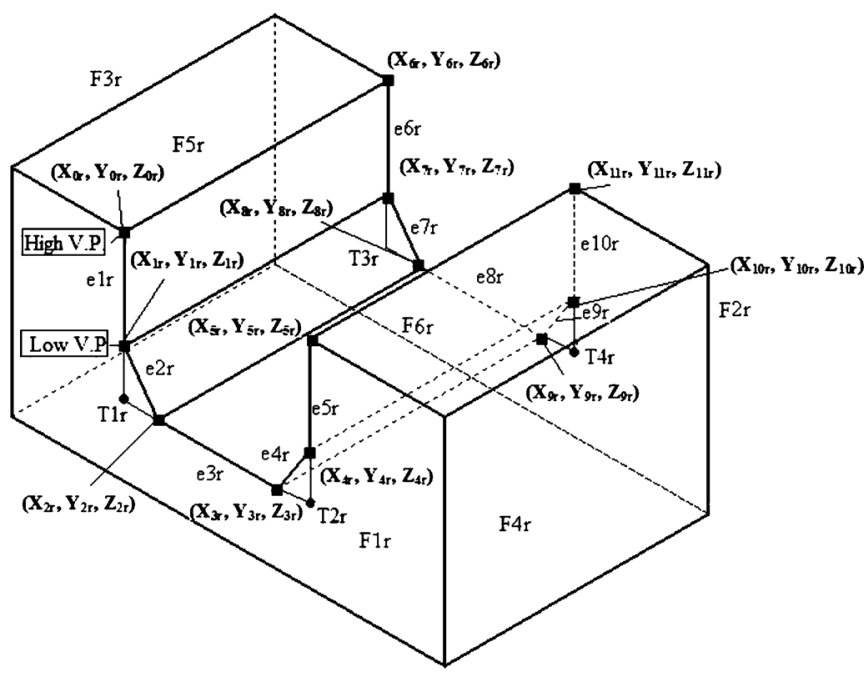

a

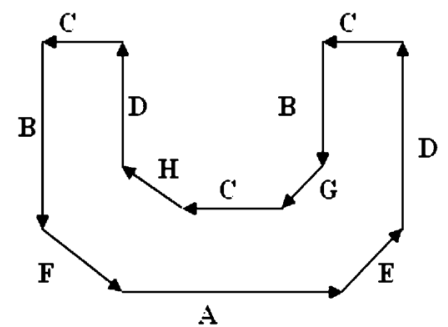

C

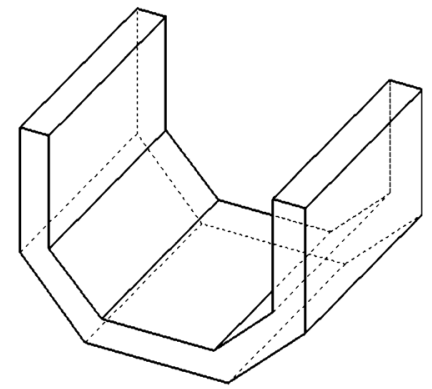

d

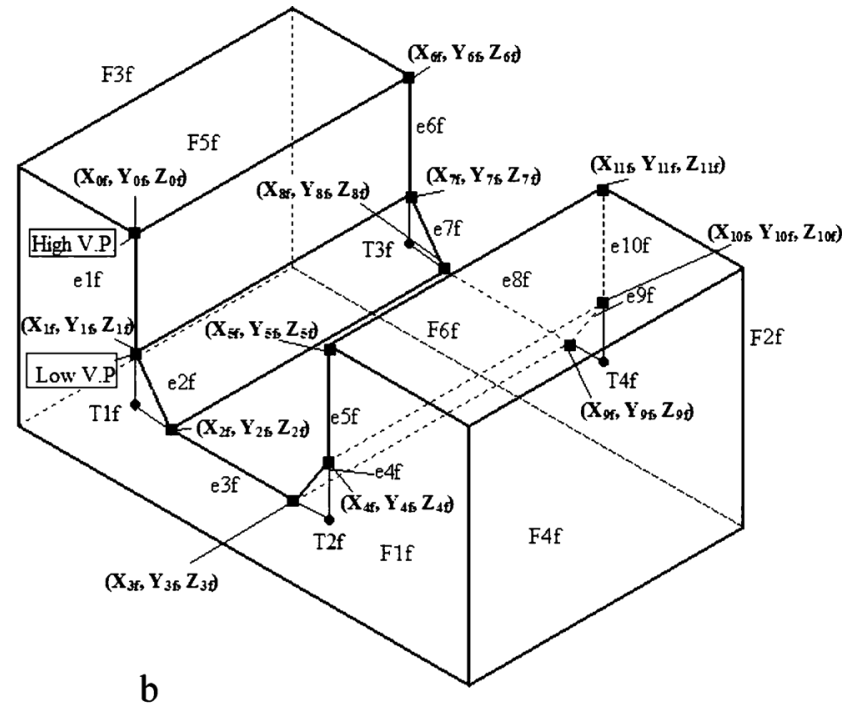

$\mathrm{OW}\left(\mathrm{W}_{4 \mathrm{r}}\right)$
$\mathrm{OH}$

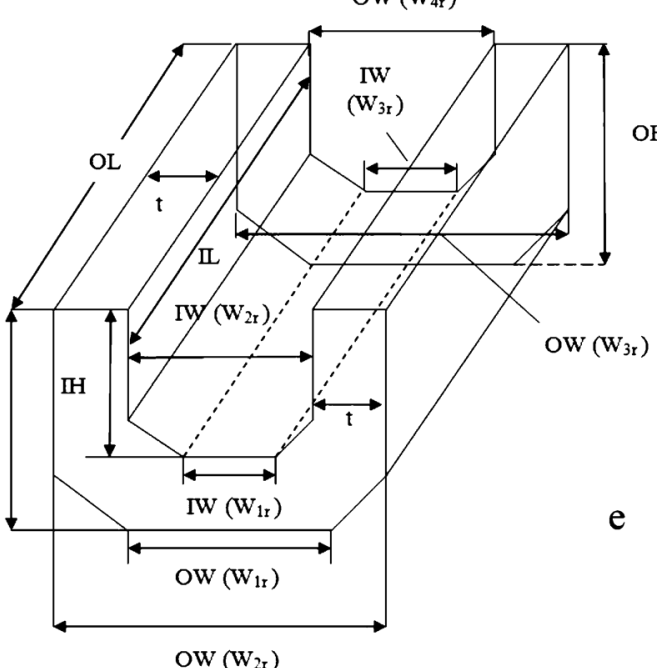

Fig. 7 a Rough-machined part with the feature through slot with blending edge; $b$ final part with the feature through slot with blending edge, $c$ predefined vector for the feature through slot with blending edge, $\mathrm{d}$ machinable volume for the feature through slot with blending edge, e schematic representation representing the notations involved in machinable volume. 
Fig. 8 Example prismatic part showing internal and external features

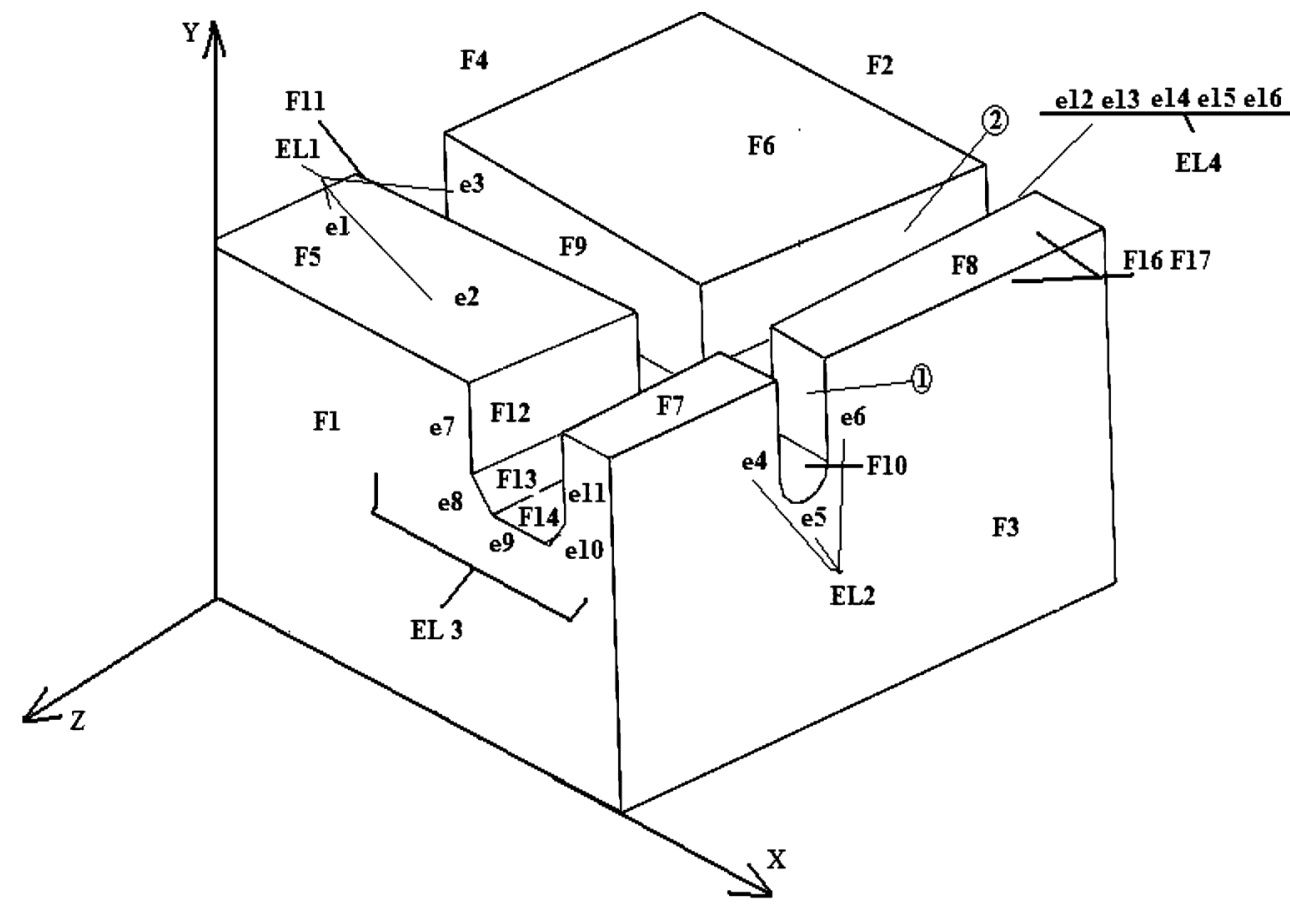

1 - Ordinary Through Slot with Curved Base Narrowing at the End [OTSLCBNE]

2 - Ordinary Through Slot with Blending Edge Narrowing at the End [OTSLBENE]

Table 3 Details of other features and machinable volumes for the example prismatic part

\begin{tabular}{|c|c|c|c|c|c|}
\hline $\begin{array}{l}\text { S. } \\
\text { no }\end{array}$ & Feature name & $\begin{array}{l}\text { Placement in } \\
\text { the plane and } \\
\text { face }\end{array}$ & $\begin{array}{l}\text { Edge loops } \\
\text { representing } \\
\text { the feature }\end{array}$ & $\begin{array}{l}\text { Feature type } \\
\text { matched or } \\
\text { identified }\end{array}$ & Details of the of the machinable volume \\
\hline 1. & $\begin{array}{l}\text { Ordinary through slot with } \\
\text { curved base narrowing at } \\
\text { the end }\end{array}$ & $\begin{array}{l}\text { ZY Plane } \\
F_{3} \text { and } F_{4}\end{array}$ & $\begin{array}{l}\mathrm{EL}_{1}\left[\mathrm{e}_{1}, \mathrm{e}_{2}, \mathrm{e}_{3}\right] \\
\mathrm{EL}_{2}\left[\mathrm{e}_{4}, \mathrm{e}_{5}, \mathrm{e}_{6}\right]\end{array}$ & $\begin{array}{l}\text { Through slot } \\
\text { with curved } \\
\text { base }\end{array}$ & $\begin{array}{l}l=138.03 \mathrm{~mm} ; w=26.78,14.42 \mathrm{~mm} ; 39.14,22.2 \mathrm{~mm} ; t=6.64, \\
4.12,5.72,6.18,3.89 \mathrm{~mm} ; h=51.92 \text { and } 51.23 \mathrm{~mm} ; 41.69 \\
\text { and } 32.99 \mathrm{~mm}\end{array}$ \\
\hline 2. & $\begin{array}{l}\text { Ordinary through slot with } \\
\text { blending edge narrowing } \\
\text { at the end }\end{array}$ & $\begin{array}{l}\text { XY Plane } \\
\mathrm{F}_{1} \text { and } \mathrm{F}_{2}\end{array}$ & $\begin{array}{l}\mathrm{EL}_{3}\left[\mathrm{e}_{7}, \mathrm{e}_{8}, \mathrm{e}_{9},\right. \\
\left.\mathrm{e}_{10}, \mathrm{e}_{11}\right] \\
\mathrm{EL}_{4}\left[\mathrm{e}_{12}, \mathrm{e}_{13}\right. \\
\left.\mathrm{e}_{14}, \mathrm{e}_{15}, \mathrm{e}_{16}\right]\end{array}$ & $\begin{array}{l}\text { Through slot } \\
\text { with blending } \\
\text { edge }\end{array}$ & $\begin{array}{l}l=150 \mathrm{~mm} ; \mathrm{w}=19.5,10.25,32.02,17.07,43.40,28.65,28.86 \text {, } \\
\text { 16.86, and } 35.8 \mathrm{~mm} ; t=5.69,6.32,5.48 \mathrm{~mm} ; h=30.42, \\
\text { 23.47, 34, and } 27.26 \mathrm{~mm}\end{array}$ \\
\hline
\end{tabular}

$l$ Length, $w$ width, $t$ thickness, $h$ height 

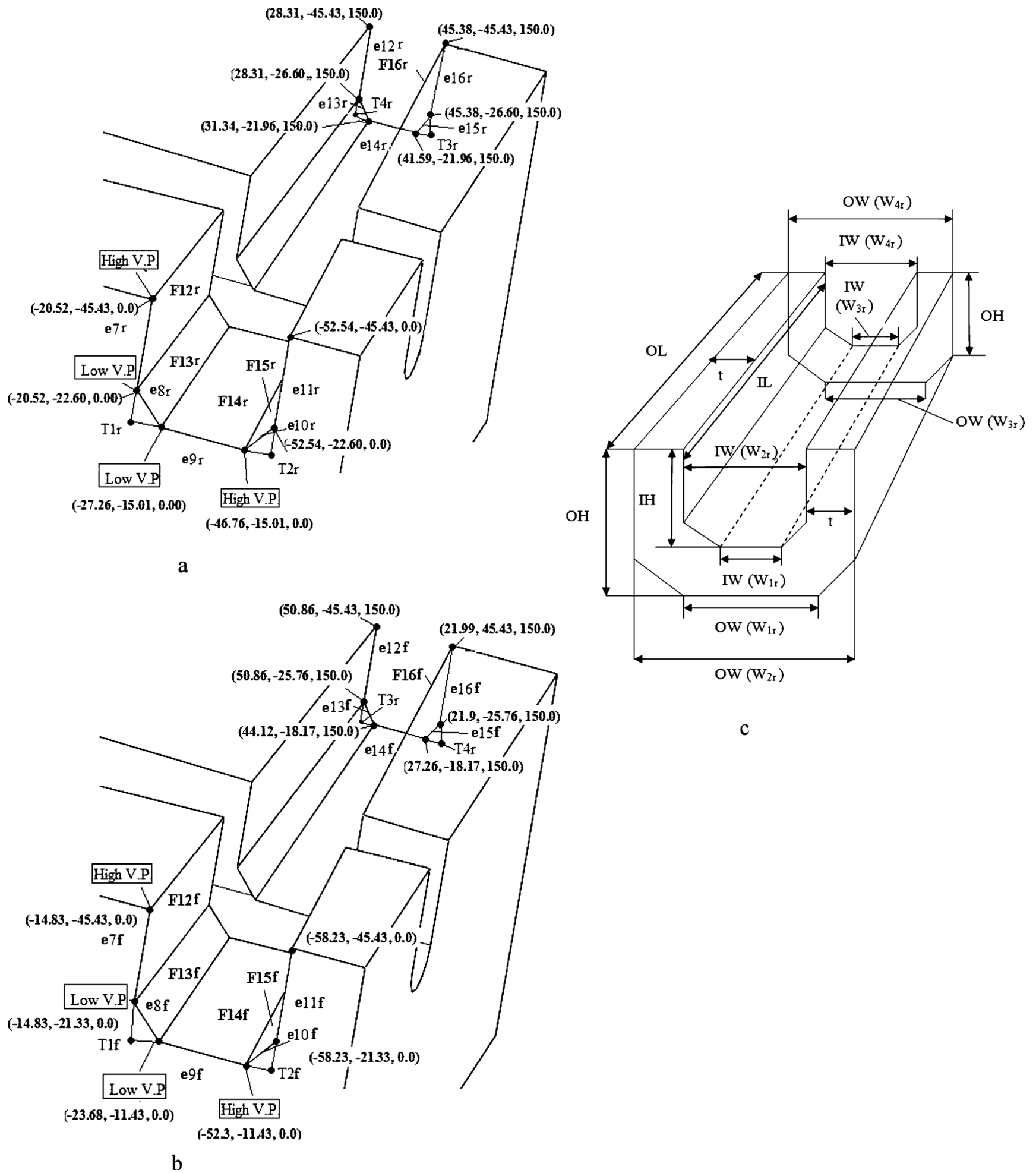

Fig. 9 a Partial view of rough-machined part with the feature OTSLBENE, b partial view of final part with the feature OTSLBENE, c machinable volume of OTSLBENE 
Table 4 Edge loop details for rough and final feature for ordinary through slot with curved base narrowing at the end

\begin{tabular}{|c|c|c|c|}
\hline S. no, & Edges & Edge loops & Details of vertex points \\
\hline \multicolumn{4}{|c|}{ 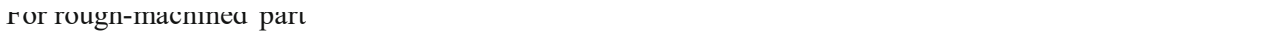 } \\
\hline 1 & $\mathrm{e}_{7 \mathrm{r}}$ & \multirow[t]{5}{*}{$\mathrm{EL}_{3 \mathrm{r}}$} & V.P $P_{1}=-20.52,-45.43,0.0 ; V . P_{2}=-20.52,-22.60,0.0$ \\
\hline 2 & $e_{8 r}$ & & V.P $P_{1}=-20.52,-22.60,0.0 ; V . P_{2}=-27.26,-15.01,0.0$ \\
\hline 3 & $e_{9 r}$ & & V.P $P_{1}=-27.26,-15.01,0.0 ; \mathrm{V} \cdot \mathrm{P}_{2}=-46.76,-15.01,0.0$ \\
\hline 4 & $\mathrm{e}_{10 \mathrm{r}}$ & & V.P $P_{1}=-46.76,-15.01,0.0 ; \mathrm{V} \cdot \mathrm{P}_{2}=-52.54,-22.60,0.0$ \\
\hline 5 & $\mathrm{e}_{11 \mathrm{r}}$ & & $\mathrm{V} . \mathrm{P}_{1}=-52.54,-22.60,0.0 ; \mathrm{V} \cdot \mathrm{P}_{2}=-52.54,-45.43,0.0$ \\
\hline 6 & $\mathrm{e}_{12 \mathrm{r}}$ & \multirow[t]{5}{*}{$\mathrm{EL}_{4 \mathrm{r}}$} & V.P $P_{1}=28.31,-45.43,150.0 ; \mathrm{V} . \mathrm{P}_{2}=28.31,-26.60,150.0$ \\
\hline 7 & $\mathrm{e}_{13 \mathrm{r}}$ & & V.P $P_{1}=28.31,-26.60,150.0 ; V^{\prime} \cdot P_{2}=31.34,-21.96,150.0$ \\
\hline 8 & $\mathrm{e}_{14 \mathrm{r}}$ & & V.P $P_{1}=31.34,-21.96,150.0 ; V^{\prime} \cdot P_{2}=41.59,-21.96,150.0$ \\
\hline 9 & $\mathrm{e}_{15 \mathrm{r}}$ & & V.P $P_{1}=41.59,-21.96,150.0 ; V^{\prime} P_{2}=45.38,-26.60,150.0$ \\
\hline 10 & $e_{16 r}$ & & V.P $P_{1}=45.38,-26.60,150.0 ; V^{\prime} P_{2}=45.38,-45.43,150.0$ \\
\hline \multicolumn{4}{|c|}{ For final part } \\
\hline 11 & $\mathrm{e}_{7 \mathrm{f}}$ & \multirow[t]{5}{*}{$\mathrm{EL}_{3 \mathrm{f}}$} & V.P. ${ }_{1}=-14.83,-45.43,0.0 ; \mathrm{V} \cdot \mathrm{P}_{2}=-14.83,-21.33,0.0$ \\
\hline 12 & $\mathrm{e}_{8 \mathrm{f}}$ & & V.P $P_{1}=-14.83,-21.33,0.0 ; V \cdot P_{2}=-23.68,-11.43,0.0$ \\
\hline 13 & $e_{9 f}$ & & V.P. $P_{1}=-23.68,-11.43,0.0 ; \mathrm{V} . \mathrm{P}_{2}=-52.3,-11.43,0.0$ \\
\hline 14 & $\mathrm{e}_{10 \mathrm{f}}$ & & $\mathrm{V} . \mathrm{P}_{1}=-52.3,-11.43,0.0 ; \mathrm{V} . \mathrm{P}_{2}=-58.23,-21.33,0.0$ \\
\hline 15 & $\mathrm{e}_{11 \mathrm{f}}$ & & V.P $P_{1}=-58.23,-21.33,0.0 ; \mathrm{V} . \mathrm{P}_{2}=-58.23,-45.43,0.0$ \\
\hline 16 & $e_{12 \mathrm{f}}$ & \multirow[t]{5}{*}{$\mathrm{EL}_{4 \mathrm{f}}$} & V.P $P_{1}=50.86,-45.43,150.0 ; \mathrm{V} . \mathrm{P}_{2}=50.86,-25.76,150.0$ \\
\hline 17 & $e_{13 \mathrm{f}}$ & & V.P $P_{1}=50.86,-25.76,150.0 ; V . P_{2}=44.12,-18.17,150.0$ \\
\hline 18 & $\mathrm{e}_{14 \mathrm{f}}$ & & V.P $P_{1}=44.12,-18.17,150.0 ;$ V.P $P_{2}=27.26,-18.17,150.0$ \\
\hline 19 & $\mathrm{e}_{15 \mathrm{f}}$ & & V.P $P_{1}=27.26,-18.17,150.0 ; V . P_{2}=21.9,-25.76,150.0$ \\
\hline 20 & $e_{16 f}$ & & V.P $P_{1}=21.9,-25.76,150.0 ; V . P_{2}=21.99,45.43,150.0$ \\
\hline
\end{tabular}

\section{References}

1. Nagaraj HS, Gurumoorthy B (2002) Machinable volume extrac- tion for automatic process planning. IIE Trans 34:393-410

2. Lin AC, Lin SY (1998) A volume decomposition approach to process planning for prismatic parts with depression and protru- sion design features. Int J Comput Int Manuf 11(6):548-563 doi:10.1080/095119298130570

3. Vujosevic R, Kusiak A (1992) Selection of machinable volumes an object-oriented approach. Exp. Sys App 4:273-283 doi:10.1016/09574174(92)90063-X

4. Lim T, Corney JR, Clark JER (2001) A laminae approach to constructing geometric feature volumes. ACM Comp Surv 183- 193 doi: $10.1145 / 376957.376979$

5. Jain PK, Mehta NK, Pandey PC (1998) Automatic cut planning in an operative process planning system.. Proc Inst Mech Eng B212:129-140 doi:10.1243/0954405981515554

6. Hebbal S, Mehta NK (2001) Extraction of depression type features of prismatic parts from their CAD models. Proc of 12th DAAAM Int Symp on Manuf and Auto October:179-180

7. Hebbal S, Mehta NK (2002) Methodology for extraction of protrusion type features and interacting depression type features of prismatic parts from their CAD model. 18th Int. Conf on CAD/ CAM, Robo. and Fact of Future, Porto, Portugal

8. Sandiford D, Hinduja S (2001) Construction of feature volumes using intersection of adjacent surfaces. Comput Aided Des 33:455-473 doi:10.1016/S0010-4485(00)00096-8

9. Woo Y, Sakurai H (2002) Recognition of maximal features by volume decomposition. Comput Aided Des 34:195-207 doi:10.1016/S00104485(01)00080-X

10. Little G, Tuttle R, Clark DER, Corney J (1997) The Heriot-Watt feature finder: A graph-based approach to recognition. Proceed- ings of DETC, ASME, Desi Eng Tech Conf, September 14-17, DETC97/CIE-4426, 1-9.

11. Little G, Tuttle R, Clark DER, Corney J (1998) A feature complexity Index. Proc of Inst of Mech Eng, Part C, J of Mech Eng Sc 212:405412

12. Gaines DM, Hayes CC (1999) CUSTOM-CUT: a customizable feature recognizer. CAD 31:85-100

13. Satish VV, Motipalli K, Prakash K (2006) Automation of process planning for boring of turned components with arbitrary internal geometry from a semi-finished stock. J Comput Inf Sci Eng 6:49- 59 doi:10.1115/1.2173670

14. Zhu H, Menq CH (2002) B-Rep model simplification by automatic fillet/round suppressing for efficient feature recogni- tion. Comput Aided Des 34:109-123 doi:10.1016/S0010-4485 (01)00056-2

15. Fu MW, Ong SK, Lu WF, Lee IBH, Nee AYC (2003) An approach to identify design and manufacturing features from a data exchange part model. Comput Aided Des 35:979-993 doi:10.1016/S0010-4485(02)00160-4

16. Jia Q, Marefat MM (2003) A Dempster-Shafer approach for recognizing machine features from CAD models. Produ Res 36:1355-1368

17. Gao S, Shah JJ (1998) Automatic recognition of interacting machining features based on minimal condition sub graph. Comput Aided Des 30(9):727-739 doi:10.1016/S0010-4485(98) 00033-5

18. Onwubolu GC (1999) Manufacturing features recognition using back propagation neural networks. J Intell Manuf 10:289-299 doi:10.1023/A:1008904109029 
19. Sommerville MGL, Clark DER, Corney JR (2001) Viewer centered geometric feature recognition. J Intell Manuf 12:359- 375 doi:10.1023/A:1011219517642

20. Liu S-C (2004) Feature extraction and classification for rotational parts taking 3D data files as input. J Chin Inst Ind Eng 21(5):432- 443

21. Aslan E, Seker U, Alpdemir N (1999) Data extraction from CAD model for rotational parts to be machined at turning centers. Tr JEng Environ Sc 23:339-347

22. Lee Y-H, Moon S, Lee H (1997) A new approach for automated parts recognition using time series analysis and neural networks. J Intell Manuf 8:167-175 doi:10.1023/A:1018565022922

23. Lee HC, Jhee WC, Park H-S (2007) Generative CAPP through projective feature recognition. Comput Ind Eng 53:241-246 doi:10.1016/j.cie.2007.06.015

24. Sheen B-T, You C-F (2006) Machining feature recognition and tool-path generation for 3-axis CNC milling. Comput Aided Des 38:553-562 doi:10.1016/j.cad.2005.05.003

25. Subramanian S, Wozny M (1995) An overview of automatic feature recognition techniques for CAPP. Comput Ind 26:1-21 doi:10.1016/01663615(95)80003-4

26. McCormack AD, Ibrahim RN (2002) Process planning using adjacency-based feature extraction. Int J Adv Manuf Technol 20:817-823 doi: $10.1007 / \mathrm{s} 001700200222$

27. Han JH (1999) Manufacturing feature recognition and its integration with process planning. ACM Sur January:108-118

28. Dereli T (1998) Development of process planning system for prismatic parts. Ph.D Thesis. Dep Mech Eng. Univ of Gaziantep, Gaziantep

29. Kang M, Han J, Moon JG (2003) An approach for interlinking design and process planning. J Mater Process Technol 39:589-595 doi:10.1016/S0924-0136(03)00516-8

30. Li WD, Ong SK, Nee AYC (2002) Recognizing manufacturing features from a design-by-feature model. Comput Aided Des 34:849-868 doi:10.1016/S0010-4485(01)00156-7

31. Defense Logistics Agency (2006) STEP Application Handbook. Defense Logistics Agency, Fort Belvoir

32. Arivazhagan A, Mehta NK, Jain PK (2007) Development of feature recognition module for tapered and curved base features. Int J Adv Manuf Technoldoi:10.1007/s00170-007-1212-8

33. Fu KS (1982) Syntactic pattern recognition and applications. Prentice Hall, Englewood Cliffs ISBN: 0-13-880120-7 